\title{
Benchmarking multi-criteria evaluation methodology's application for the definition of benchmarks in a negotiation-type public-private partnership. A case of study: the integrated action programmes of the Lazio Region
}

\author{
Department of Architecture and Design, \\ Sapienza University of Rome, \\ Italy \\ Email: mariarosaria.guarini@uniroma1.it \\ Email: fabrizio.battisti@uniroma1.it \\ *Corresponding author
}

Maria Rosaria Guarini* and Fabrizio Battisti

\begin{abstract}
The growing scarcity of public financial in Italy, in opposition of the more significant problems of degradation of many urban areas, prompted the Legislature to standardise new processes of settlement transformation based on negotiation-type public-private partnerships (PPPN). However, these standards have not provided for benchmarks referring to the contents of partnerships or assessment procedures aimed at assessing the initiatives undertaken with respect to public utility objectives. This has often led to redevelopment initiatives geared more towards the satisfaction of private rather than public interests. The proposed methodology, structured on the integration of a benchmarking process with multi-criteria evaluation techniques known as benchmarking multi-criteria evaluation (BME) enables the definition of benchmarks through a participatory process of the different stakeholders involved in a PPPN to which the BME is applied. In order to verify the applicability of the proposed procedure, it has been applied to a type of PPPN: the integrated action programmes (PII) in the Lazio Region. The benchmarks can be used by Lazio's administrators both for renewing the planning of the PII concerned and for verifying the quality of the initiatives within the same PPPN process.
\end{abstract}

Keywords: appraisal; multi-criteria analysis; MCA; public-private partnership; PPP; benchmarking; stakeholders; governance.

Reference to this paper should be made as follows: Guarini, M.R. and Battisti, F. (2014) 'Benchmarking multi-criteria evaluation methodology's application for the definition of benchmarks in a negotiation-type public-private partnership. A case of study: the integrated action programmes of the Lazio Region', Int. J. Business Intelligence and Data Mining, Vol. 9, No. 4, pp.271-317.

Biographical notes: Maria Rosaria Guarini holds a $\mathrm{PhD}$ in documentation, cataloguing, analysis and reuse of cultural heritage. She is author and co-author of published works on various topics, about the themes of real estate market, urban planning and cultural heritage and museum structures (economic and environmental evaluation, programming, planning and management, elaboration of models for the activation of decision). She has been member (May 2005-April 2009) of the 'Unit of Evaluation and Verification of Public 
Investments' of the Italian Ministry of Cultural Heritage and Cultural Activities. Currently, she is an Assistant Professor in Real Estate Appraisal at the Sapienza, University of Rome, Italy.

Fabrizio Battisti holds a PhD in Redevelopment and Settlement Recovery. He is author and co-author of published works on various topics, especially about the themes of multi-criteria decision analysis and its application, real estate market and urban planning. He has been Contract Professor (2010-2014) in Real Estate Appraisal at the Sapienza, University of Rome. Currently, he is a Research Fellow in Real Estate Appraisal, with a research project concerning the use of multi-criteria analysis in urban development process, at Department of Architecture and Design at the Sapienza, University of Rome, Italy.

This paper is a revised and expanded version of a paper entitled 'Benchmarking multi-criteria evaluation: a proposed method for the definition of benchmarks in negotiation public-private partnerships' presented at 14th International Conference on Computational Science and its Applications (ICCSA 2014), Guimaraes, Portugal, 30 June to 3 July 2014.

\section{Introduction}

Most of the activities related to territorial administration (for both redevelopment and development), as currently (2014) implemented by the majority of Italian local governments, are based on public-private partnership (PPP). Processes implemented through PPP make it necessary the search for a balance between public and collective interests, of which the public administration (PA) is the carrier, and the interests of which private entities are the carriers.

Exclusively public intervention in redevelopment and recovery initiatives for settlements has become an 'extreme' modus operandi creating major problems related to the identification of investment and management resources in particular (Curti, 2007).

In the 1990s, and then more recently during the current economic downturn (2008-2014), scientific debate (both European and Italian) was aimed at identifying action strategies to address the problems regarding the 'urban dimension'; in particular, this debate has focused on the definition of new procedures able to generate growth, competitiveness and physical renewal of the territory through urban redevelopment and limiting the use of public resources. In this context, the subject of the PPP has assumed particular importance. In this respect, the European Union has introduced instruments, which have then been implemented by the Member States, which provide for recourse to PPPs, both to activate wider negotiation-type processes for territorial redevelopment $(\mathrm{PPPN})^{1}$ and to undertake traditional works of public interest (PPPT) ${ }^{2}$.

With reference to the territorial redevelopment process, starting in the 1990s, Italy followed the European experience and issued 'innovative' standards, introducing new planning instruments: the so-called complex programmes ${ }^{3}$ (integrated intervention 
programmes, urban redevelopment programmes and urban rehabilitation programmes) pertaining to the PPPN. These instruments are more flexible than the traditional authoritative territorial government models used by the $\mathrm{PA}^{4}$; in initiatives under the complex programmes, the PA can in fact 'soften' the exercise of its urban planning authority by negotiating proposals submitted also by private entities, as an exception to municipal planning instruments.

At national and regional level, these instruments have been standardised, with legislative devices containing general principles; implementing regulations ${ }^{5}$ and/or memoranda regarding the method of preparation, evaluation (ex ante, in itinere and ex post), implementation and management of initiatives to be activated with these instruments have almost never been issued. Consequently, specific indicators by which to measure and compare the expected effects of the initiatives to be activated or that have been activated have not been identified.

Due to technical difficulties and/or the discretion that the policy maker sometimes reserves in implementing territorial redevelopment programmes based on PPPN, local governments have rarely developed protocols of direction containing specific benchmarks to transparently verify both the equity of treatment among private parties and, especially, the suitability of the proposed initiative in terms of collective and social objectives $^{6}$, also through the use of appropriate appraisal techniques (Morano and Tajani, 2014b).

In this context, the first PPPN experiences launched in Italy, promoted almost exclusively by private operators and built on 'generic' references to the law, were therefore used more to act as driving forces for low-risk financial profit, without commitments and special guarantees for the public, rather than achieving public interest objectives (Urbani, 2007).

However, within a complex and overall vision (multiplicity of objectives, types of interventions, stakeholders involved) of the modalities of planning and implementing PPPN processes, particular importance should instead be given to the distribution of commitments and conveniences between public and private operators (Morano and Tajani, 2013).

In fact, on the Italian scene this is one of the critical situations found in initiatives planned and implemented with such programmes and is also attributable to the lack and/or inappropriate use of assessment instruments supporting the choice of decisions to be taken.

Useful indications for responding to this problem can be found in several EU directives which have recognised the use of assessment techniques and instruments ${ }^{7}$ to support decisions related to the planning of complex territorial redevelopment processes. Among these, assessment techniques such as benchmarking ${ }^{8}$ (BCM) (Karloff and Ostblom, 1993; Camp, 1996) and multi criteria analysis ${ }^{9}$ (MCA) are or particular interest (Nijikamp et al., 1990; Keeney and Raiffa, 1993; Lichfield et al., 1998).

Already during the late 1990s, the European Commission recognised the BCM as an "integrator of quality processes and stimulator of learning processes both in industries and in different situations, such as PA" (European Commission, 1997). In this sense, the 
BCM was intended as an instrument to cyclically and continuously improve the performance of a company or a PA, insofar as it allows a comparison of social behaviour, business practices, market structures, and public, national, regional, sectoral and corporate institutions, also in the light of the continuous evolution of the social and economic framework within which the same PA and/or businesses operate.

In 2005, the European Commission recognised the MCA as a useful assessment instrument to be used in complex situations involving stakeholders with different objectives, roles, positions, interests and opinions ${ }^{10}$ (European Commission, Europe Aid Cooperation Office, 2005).

These assessment instruments assume greater effectiveness when all 'decision maker' stakeholders are considered and when methods and techniques are used to encourage their participation through consultation and interaction and for the resolution of conflicts which may arise among the expectations of different stakeholders (Guarini and Battisti, 2014a).

These assessment methods and techniques, widespread at European level, have only found marginal recognition in Italian legislation ${ }^{11}$ and practice. Nevertheless, in scientific circles there are many different proposals for the application and experimentation of these techniques (BCM and MCA).

However, an integrated and joint application of these two inclusive ${ }^{12}$ and complex ${ }^{13}$ assessment procedures has never been proposed (Nijikamp et al., 1990; Keeney and Raiffa, 1993; Lichfield et al., 1998; Roscelli, 2005; Mattia, 2007; Fusco Girard and Nijkamp, 2012; Battisti, 2012).

It is believed that the contextual and integrated application of procedures relating to the BCM and the MCA can be used for the participatory definition of objective and shared performance references (benchmarks) of levels of quality aimed at improving efficiency, effectiveness and transparency in negotiation-type partnership territorial redevelopment processes (Guarini and Battisti, 2014b).

With reference to the redevelopment instruments based on the PPPN, the benchmarks resulting from a process of this type may provide useful elements for combining private and public viewpoints.

\section{Aims}

This document is part of the debate mentioned with the explicit aim of proposing a benchmarking multi-criteria evaluation (hereinafter BME) method that enables identification of benchmarks (in relation to ex post assessments of experiences, preferably virtuous, already carried out) to guide the planning of PPPN-based processes and/or training for and/or assessment (ex ante) of new initiatives (Guarini and Battisti, 2014b).

The BME, structured on the BCM and the MCA, will act as support to improve the transparency and effectiveness of the administrative activities of the PA in the territorial government (planning processes, training, validation and implementation of settlement 
transformation initiatives), by focusing on the interaction between public and private partners regarding their conveniences (balance of resources used and produced, risks and guarantees).

The BME is calibrated in this text, which illustrates the methodological proposal, and in its application verification to be applied, in the Italian context, to PPPN-based urban redevelopment processes, but it could also be used in settlement transformation processed based on the PPPT. Moreover, it is believed that the BME can also be used with reference to other European and international contexts.

The method proposed is shown below, and described in Section 3: the proposed methodology: BME, sections: 3.1: purpose and use; 3.2: structure; 3.3: method of implementation of the different phases. The application's verification of the methodology has been developed on a meaningful sample of PII, and described in Section 4: application of the BME to the integrated action programmes (L.R. 22/1997) of the Lazio Region, sections: 4.1: choice of the negotiation-type PPPs on which to apply the BME: the integrated action programmes of the Lazio Region; 4.2: plan; 4.3: do; 4.4: check; 4.5: act. In Section 5, the conclusions of the work are derived.

\section{The proposed methodology: BME}

\subsection{Purpose and use}

In the BME, the MCA is implemented within a BCM model, the Deming cycle, to activate a multi-dimensional learning and change process as part of PPPN-based territorial redevelopment processes and initiatives.

The BME is aimed at defining benchmarks (performance references) designed to improve quality standards (in an objective way that is shared among the stakeholders involved) of any new planning of such processes and of the initiatives through which they are implemented.

The benchmarks are performance for which stakeholders express sufficient satisfaction at the very least. Therefore, they can be parameters useful to the $\mathrm{PA}^{14}$ (provincial, regional and local) that must both define guidelines for the planning of these processes and be expressed when the contents of the individual initiatives proposed are approved.

In particular, the benchmarks resulting from the application of BME can be used:

- by PAs with planning and authorisation responsibility for initiatives related to these instruments. For this purpose, explanatory and policy-making instruments must be structured and organised by the PAs (e.g., guidelines, implementing regulations, strategy memoranda)

- by promoters of initiatives relating to individual processes in order to align their proposals to the references assumed as a direction from the PAs. 
A municipal PA could make use of the BME to evaluate its actions with respect to any specific PPPN processes and to define the trends that must be followed in order to promote initiatives in its territory aligned with quality standards (restricted territorial scope). However, at the local level, a significant and satisfying number of initiatives of the same process for which the BME was implemented may not have been started; this would result in the low significance of the results of this method.

Therefore, use of the method at provincial level, but above all regional level (vast territorial scope), assumes greater interest; in vast but nevertheless homogenous territorial areas, it may be the starting point for stimulating local administrations towards 'learning' and 'improvement' of their assets, by borrowing the best practices promoted at their territorial level (homogenous), insofar as it permits a comparison of the work of different local PAs, being able to consider a significant sample of initiatives.

Cyclic application of the BME may enable the achievement of increasingly better and shared performance appropriate to the PPPN reference framework for which the same BME was implemented.

\subsection{Structure}

The BME is structured as a Deming cycle in which the assessment nodes are resolved through MCA techniques (in order to permit the assessment of different, and sometimes heterogeneous, aspects that characterise the PPPN processes) as well as through logical and mathematical functions.

The BME is an assessment instrument that can be used by a PA that considers it necessary to perfect the activity related to a specific territorial redevelopment process based on the PPPN. Better results are achieved if the BME is applied to processes in which a large number of significant initiatives are implemented.

Once the specific PPPN to be assessed is identified, it is possible to launch the BME, which is divided into four macro phases:

1 the plan phase, designed to identify the key elements for subsequent implementation of purely assessment phases (do and check): survey and analysis of the initiatives (adopted and approved) in the specific PPPN process taken into consideration, and recognition of the sample of initiatives on which to implement the BME (alternatives); identification of Stakeholder categories to engage

2 the do phase, designed to define and explain all variables related to the alternatives to be considered in the assessment: construction of the impact matrix (formulation of criteria, sub-criteria and indicators), implementation of the stakeholders' analysis and construction of the matrix of viewpoints (weighting sub-criteria and objective functions); insertion of data (input) in the matrices

3 the check phase, designed to define the benchmarks: collection of opinions through appropriate MCA techniques to obtain the quality and hierarchical orders of the alternatives; identification of the most significant (best in class ${ }^{15}$ ) alternatives in relation to the level and quality of interaction and satisfaction of the main public and 
private partners and other parties involved; identification of benchmarks derived from best performance found among the alternatives

4 the act phase, designed to organise benchmarks into guidelines so that they become useful references for the forecasts and decisions to be made in new initiatives similar to those analysed in the BME process by bringing efficiency and effectiveness to the PPPN process to be improved: re-assembly of the set of benchmarks in a document, in line with the applicable legislation and regulation of the type of PPPN process to which the BME is applied.

\subsection{Implementation}

The following briefly describes the operating procedures for implementing the various BME phases (Table 1).

Table 1 BME phases

\begin{tabular}{|c|c|c|}
\hline Phases & Action & Output \\
\hline \multirow[t]{3}{*}{ Plan } & $\begin{array}{l}\text { Analysis of the initiatives } \\
\text { relating to the type of PPPN }\end{array}$ & Highlight the most significant aspect \\
\hline & Identification of alternatives & Select significant and representative initiatives \\
\hline & $\begin{array}{l}\text { Identification of } \\
\text { stakeholder (Stk) }\end{array}$ & Choice representative Stk for number and categories \\
\hline \multirow[t]{8}{*}{ Do } & Impact matrix & Criteria (environmental, procedural, socio-economic, etc) \\
\hline & & Sub-criteria relating to criteria \\
\hline & & Indicators relating to sub-criteria \\
\hline & & Input data \\
\hline & Viewpoint matrix & Weights \\
\hline & & Objective function \\
\hline & Other viewpoint & N. of alternatives to be considered best in class \\
\hline & & Satisfaction of the performance for each sub-criterion \\
\hline \multirow[t]{4}{*}{ Check } & Aggregate input data & Appraisal score \\
\hline & Classifications of alternatives & Preference order of alternatives for each Stk category \\
\hline & $\begin{array}{l}\text { Identification of performance } \\
\text { of the best in class }\end{array}$ & Average, maximum, modal performance \\
\hline & $\begin{array}{l}\text { Definition of a benchmark for } \\
\text { each sub-criterion considered }\end{array}$ & $\begin{array}{l}\text { Related to level of satisfaction of } \\
\text { best in class's performance }\end{array}$ \\
\hline \multirow[t]{2}{*}{ Act } & $\begin{array}{l}\text { Pre act: organisation of the } \\
\text { benchmarks identified }\end{array}$ & Guidelines or regulatory framework \\
\hline & $\begin{array}{l}\text { In act: approval and } \\
\text { institutionalisation } \\
\text { of the BME results }\end{array}$ & BME and benchmarks: protocol, standard, procedural \\
\hline
\end{tabular}




\subsubsection{Plan}

The following is carried out in the plan phase:

1 Analysis of the initiatives relating to the type of PPPN process to which the PA has decided to implement the BME; according to criteria (urban planning, social and procedural) through which to enable a thorough reading of the initiatives in order to highlight the most significant aspects.

2 Identification of alternatives $(A n)$ to be considered in application of the BME: verify comparability of the initiatives activated in the PPPN process to which the BME is applied and select a significant and representative sample of initiatives (alternatives). It is appropriate to select this sample if there is a large number of initiatives which, if all of them have been taken into consideration, can make the BME process particularly long or complex, or if the initiatives were activated during broader time horizons. A necessary condition for the selection of the set of alternatives is the choice of initiatives that have not only been initiated (and under investigation), but that have already been approved by the competent bodies and are covered by an urban planning agreement. In fact, they become legally valid only after approval and, in particular at the time of 'agreement' between the PA and private operator.

3 Identification of stakeholder $(S T n)$ categories to engage in the benchmark definition process. Depending on the type of PPPN process and level of detail to be given to the BME, the composition of the category and number of representatives to be interviewed will be different. Normally, because they are affected by the PPPN-based redevelopment processes, the Stakeholder categories that may be engaged in the BME are: institutions (state, regional and local), business owners, property owners, economic operators, residents, workers and tourists. The plurality of Stakeholder viewpoints is essential to give the process a suitable degree of participation and horizontal government (governance), in line with current European trends. Once the stakeholder categories are defined, it is also necessary to specify the number of subjects to be interviewed for each different stakeholder category, and to identify the contact method to be used to carry out the interviews for obtaining the opinions of the same stakeholders.

\subsubsection{Do}

The following is carried out in the do phase:

1 Construction of the impact matrix (Table 2), into which the input data representative of the performances $(i)$ related to each of the initiatives considered (significant sample) and constituting the assessment alternatives ( $A n)$, will be inserted ordinately. construction of this matrix may take place following collection, analysis and processing of data regarding:

a objectives, constraints, requirements, guidelines and specific guidelines set out in the legal systems that govern the PPPN process covered by the BME

b the alternatives considered (dimensional, financial, procedural, economic, social, administrative, etc.).

The information derived from previous analysis and processing makes it possible to: 
a Select/identify assessment criteria $(\mathrm{Cn})$, sub-criteria $(\mathrm{SCn})$ and related indicators (In) specific to the type of PPPN process in question. The criteria and subcriteria must be formulated and calibrated as the assessment proceeds in relation to the type of process to which the BME is being applied.

With reference to the indications of the European Commission:

- There are usually five categories of criteria against which to define the sub-criteria (in sufficient numbers to significantly express the transformations generated by the initiative): environmental, financial, socio-economic, procedural and technical.

- The set of sub-criteria should be a corpus that is in line with the assessment purposes and balanced (the indications must be unequivocal and, therefore, a special interest should not be measured by more than one sub-criteria) through which concrete and credible results can be achieved.

- The indicators are to be defined and explained on the basis of the possibility of:

1 using existing data that are easily and statistically comparable

2 making complex issues understandable

3 integrating with other assessment indicators.

In assessment practice, it is known that the indicators can usually refer to different scales and measures, and that they should still be related to what it is intended to describe. They may be divided into four macro-categories:

1 quantitative with legal standards, referring to all quantitative data that can be quantitatively measurable and comparable with a threshold defined by law

2 the quantitative without legal standards, referring to data that can be assessed through thresholds defined ad hoc

3 qualitative (with possible quantitative elements

4 cartographic.

b Entry of the input data of each sub-criterion for each of the alternatives in the impact matrix $[i(S C n ; A n)]$. These are deduced from all collected documents (project and administrative) regarding the alternatives considered.

c (Possible) standardisation of input data (heterogeneous) inserted into the impact matrix through:

- linear normalisation functions

- logical-mathematical functions (zero-max, min-max, max-max, vector, line total, zero mean)

- value and utility functions.

The choice of the normalisation function should be made in relation to heterogeneity/homogeneity, scrap value, impact matrix data input. This operation permits making the impact matrix homogeneous for the subsequent collection of opinions in the check phase. 
d (Possible) implementation of the dominance analysis, needed if there are some 'dominate' alternatives, in the Paretian sense, and, therefore, immediately recognisable as 'not satisfactory' at this stage, even before the collection of reviews.

2 Implementation of the stakeholder analysis by interviewing a significant sample of representatives from the various stakeholder categories involved in the type of PPPN concerned. Through the stakeholders analysis, for each category of stakeholders, it is possible to:

- Survey:

a The objective function $[f o(S C n ; A n)]$ for each indicator (related to the performance's trend). Satisfaction in relation to the performance of the indicator is detected by interviewing subjects in relation to each sub-criterion. Three performance's orientations of the objective function are usually identified: maximisation (trend toward highest values).

b Minimisation (trend toward lowest values).

c Indication of a range of values taken as the reference.

d The levels of satisfaction (very high, high medium, low and no satisfaction) of the performance for each sub-criterion.

For each sub-criterion each interviewed must express its satisfaction (very high, high, medium and low) on the value of the indicator.

- Assign weights (an indication of the importance assigned by stakeholders and/or decision-makers) to each criterion and sub-criterion $[p(S C n ; A n)]$. Through the weighing of criteria and sub-criteria is possible to define an order of importance among various criteria and/or sub-criteria. For this purpose, the following techniques are used, which are to be chosen in relation to the number of respondents and the level of 'robustness' to be achieved in the weighing of the criteria and sub-criteria: direct assignment; pairwise comparison; paired comparison technique; Delphi method; methods based on a single order.

- Define the rules for selection of the best in class. Each interviewed must express regarding the criteria of selection of the best in class.

3 Viewpoint matrix (Table 3) to explain, in a synthetic way, the preferences of a significant number of subjects ordinarily representative of the categories of Stakeholder to be considered in the assessment. To build this matrix, the data obtained through interviews must be reprocessed to obtain the following synthetic other data (for each category of stakeholders):

a the weight of criteria and sub-criteria $(p)$

b orientation of the objective functions $(f o)$

c definition of the best in class selection criteria and demarcation of the satisfaction level perceived by the stakeholder categories in relation to certain performances, as they are measured by the indicator of each sub-criterion.

The synthetic data referred to in point $\mathrm{c}$ will be used for the implementation of the BME in the next phase check. 
Table 2 Impact matrix (with the inclusion of criteria, sub-criteria and indicator examples)

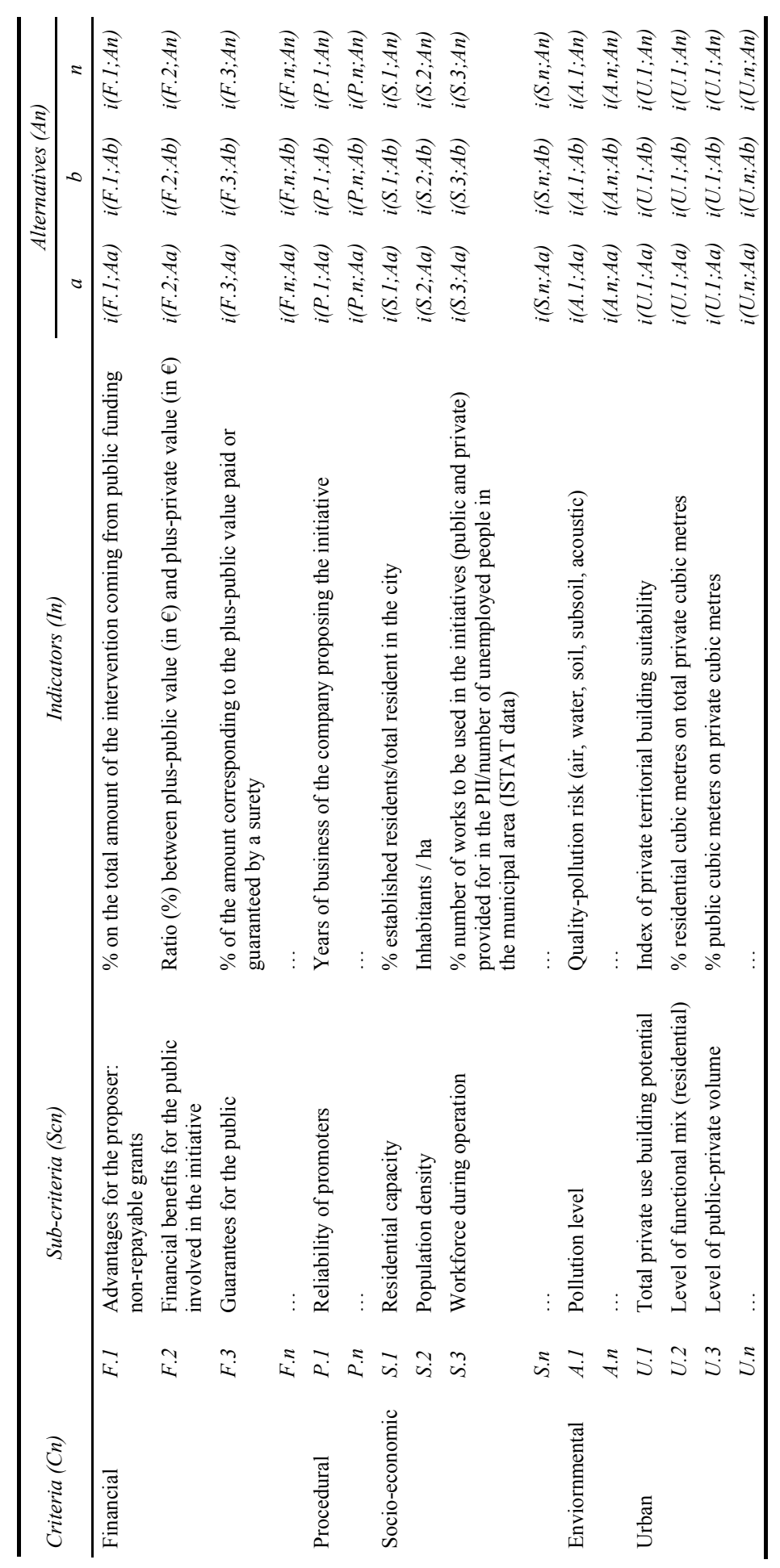


Table 3 Viewpoints matrix

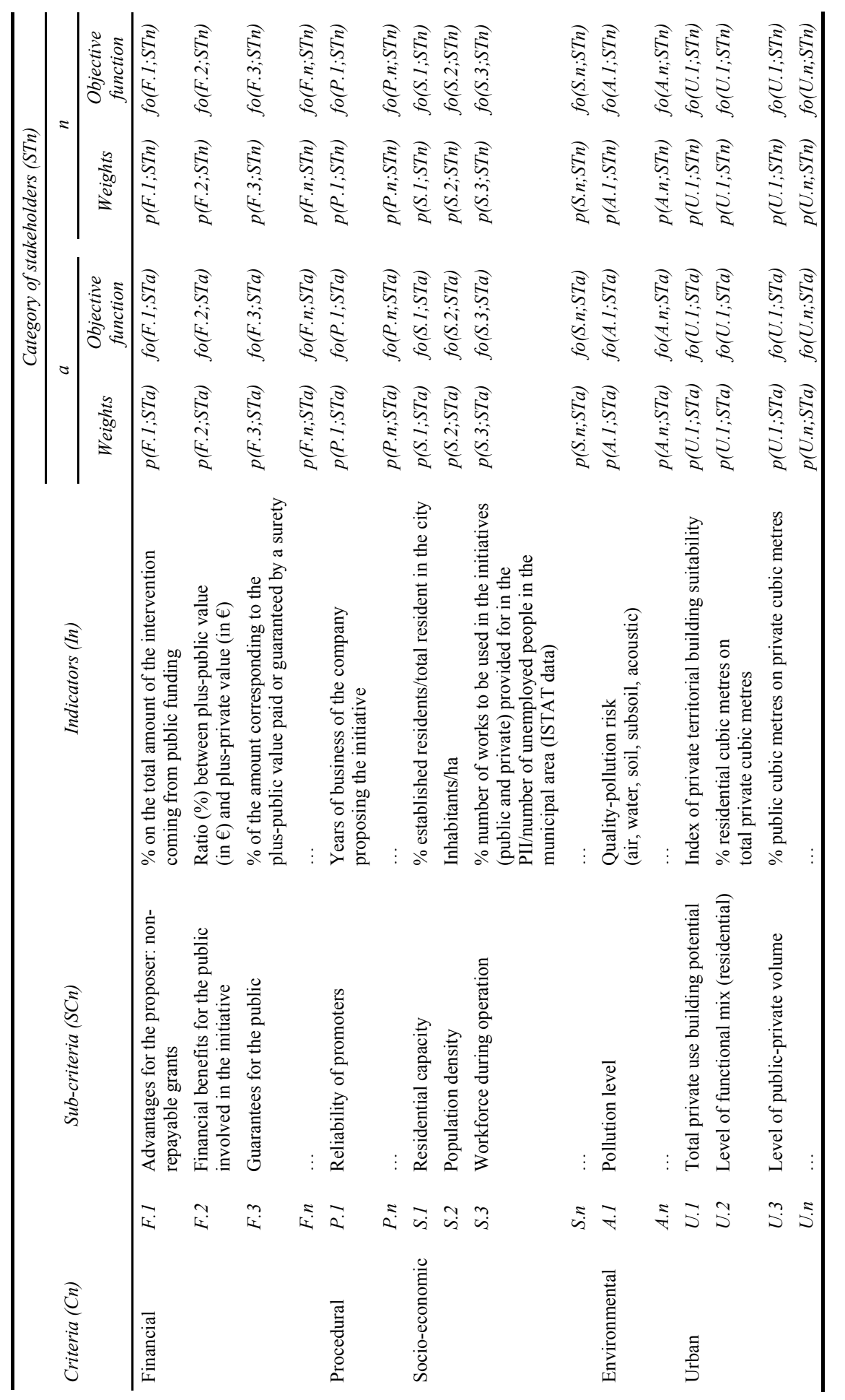




\subsubsection{Check}

The following is carried out during the check phase:

1 Aggregate input data (possibly made homogeneous) of the impact matrices and viewpoints to obtain the appraisal score (as) (output data) from which to define the hierarchy from among the alternatives considered for each category of stakeholders $[a s(A n ; S T n)]$. Opinions may be aggregated using various systems such as AHP, REGIME, ANP, MAUT, TOPSIS, NAIADE, etc.; the technique should be chosen on the basis of a number of alternatives, criteria, sub-criteria and subjects to be considered in the assessment as well as the possible legal recognition of opinion collection systems in regulations relative to the PPPN to which the BME is applied.

2 Formation of classifications (different 'single group' classifications for each Stakeholder category) indicating the preference order (pos) of alternatives for each Stakeholder category [pos(An;STn)] (Table 4).

The collection of opinions permits sorting the alternatives according to a qualitative-hierarchical order; once the classifications are defined, and the results of the stakeholders analysis are retrieved (see do phase, Section 2, point c), it is possible to define the best in class or the $\mathrm{n}$ alternatives preferred by the $\mathrm{n}$ stakeholders.

3 Identification of performance average, maximum and possibly modal of the best in class (pre-benchmark range). With the best in class performance, summary schemes are created (one for each sub-criterion) in which these values are given; subsequently, it is possible to revise such values in order to identify the average $[\operatorname{Vmed}(S C N)]$, maximum $[\operatorname{Vmax}(S C N)]$ and possibly the modal $[\operatorname{Vmod}(S C N)]$ of all the best in class of each sub-criterion (Table 5).

4 Definition of a benchmark $(B)$ for each sub-criterion considered $[B(S C n)]$. Prior to the definition of the benchmarks, the degree of satisfaction $(g)$ of the stakeholder category must be verified (defined within the stakeholders analysis, see the do phase paragraph 2 point $\mathrm{c}$ with the average ( $\mathrm{gVmed}$ ), maximum $(\mathrm{gVmAX})$ and modal $(\mathrm{gVmod})$ values of the best in class. This permits verification of the satisfaction level for each Stakeholder category $[g(S C n ; S T n)]$ and consequently the 'acceptability' of the references identified. Once this verification is completed, the value (average, maximum and eventually modal) for which there is the greatest satisfaction for most categories of stakeholders can become a benchmark.

The satisfaction expressed by the categories of stakeholders to the value that becomes the benchmark, however, must be 'average' (better 'high' or 'very high') for each category of stakeholders. If situations do not occur linear (opinions of the categories of stakeholders are not shared about the average, maximum and eventually modal values), the benchmark can also be defined as the interpolated value between the previous values (average, maximum, modal).

The choice of benchmarks always depending on the level of satisfaction expressed by categories of stakeholders; it always better to take as benchmarks values for which there is shared satisfaction among categories of stakeholders. Defined benchmarks must be checked if there is consistency with the legislation that governs the process type for which the BME has been implemented (Table 6). 
Table 4 Single group rankings and definition of the best in class (with sample positioning)

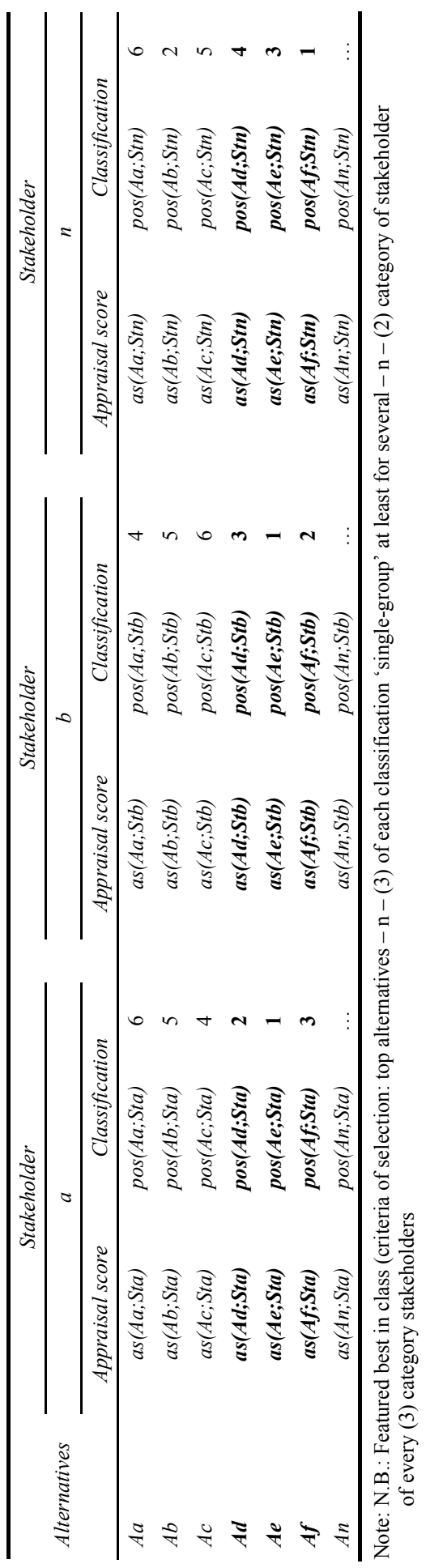


Table 5 Definition of the pre-benchmark range (with examples of pre-benchmarks)

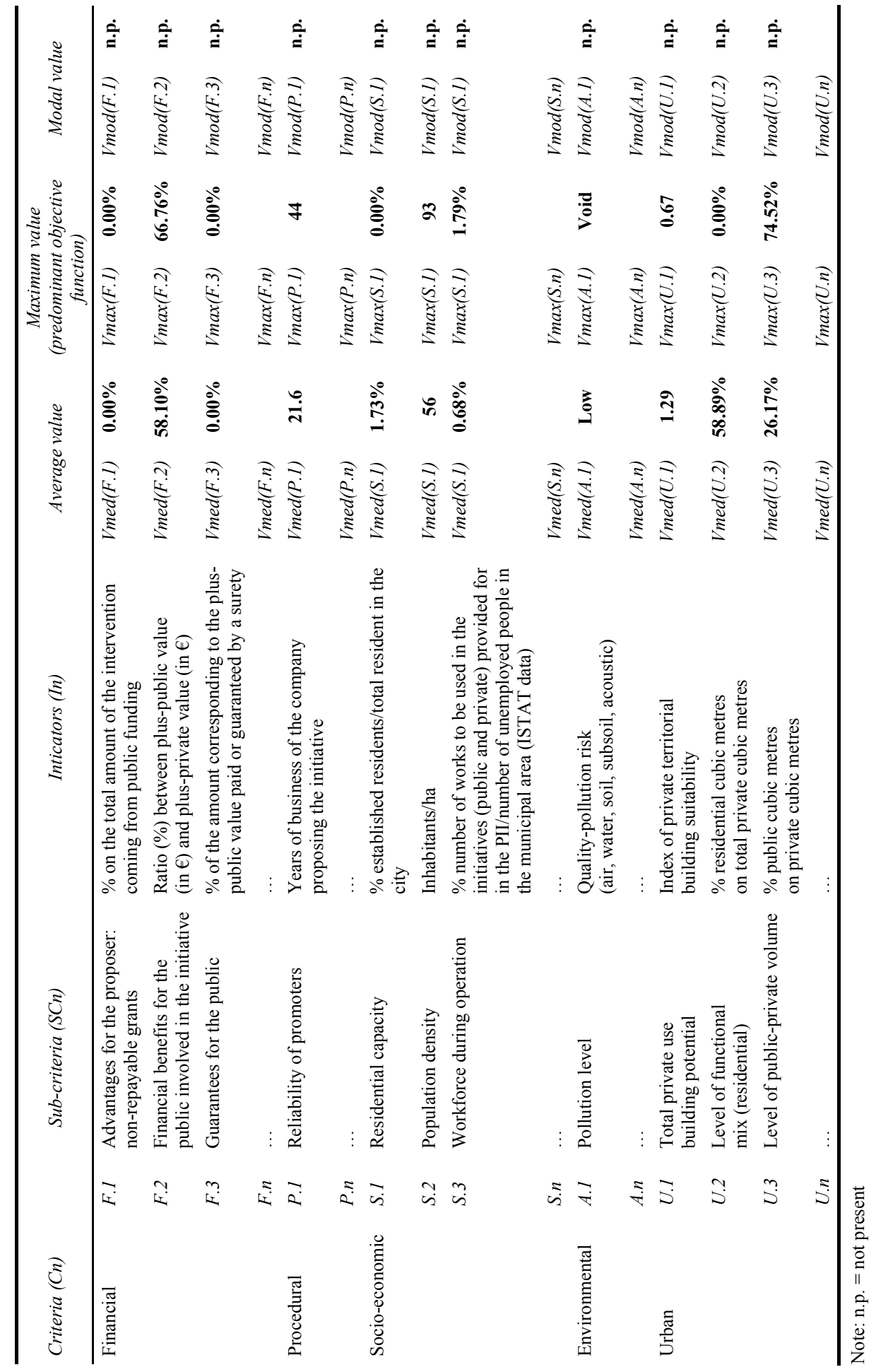


Table 6 Verify the stakeholders' acceptability of the average and maximum values (with examples of satisfaction) and benchmarks proposal (examples of benchmarks)

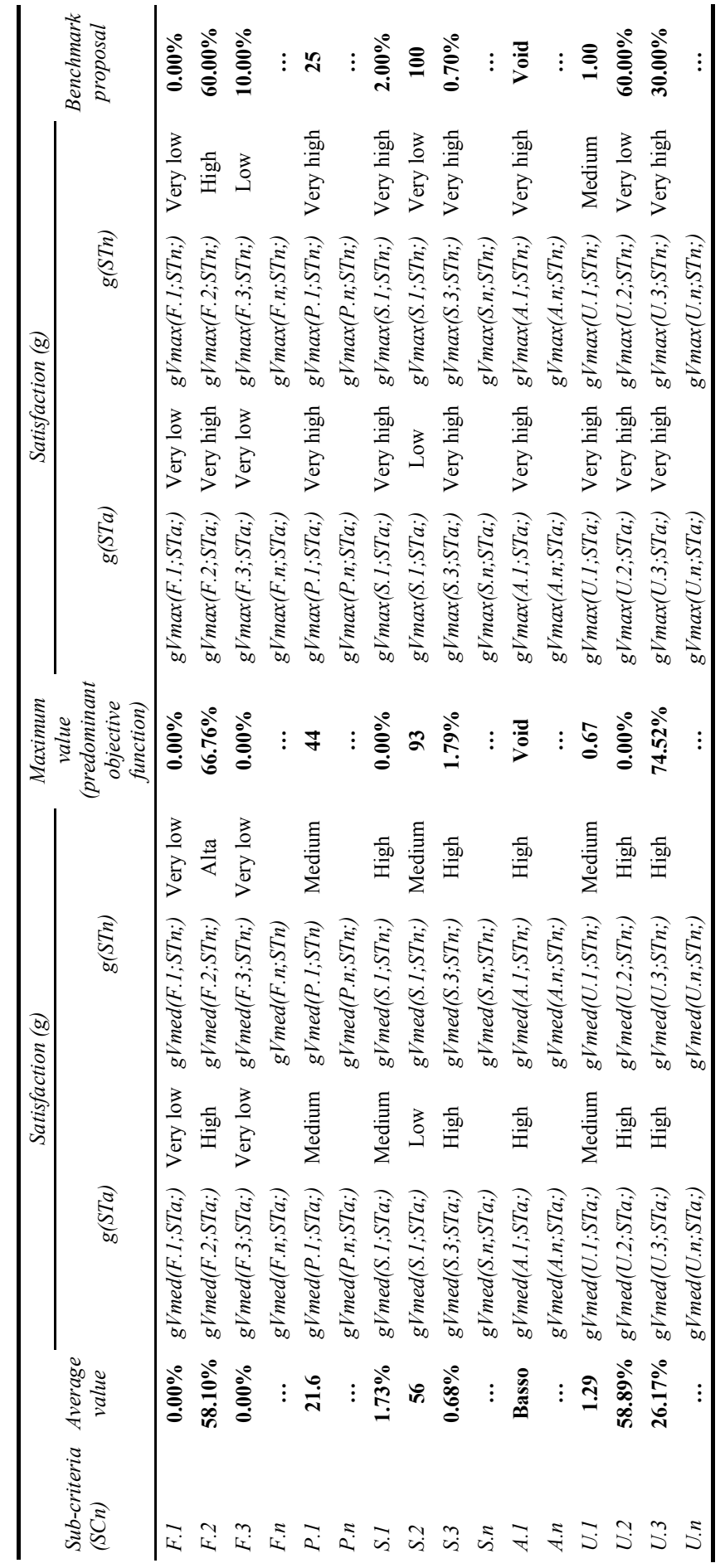


If the benchmarks obtained are inconsistent according to the latter, the causes of the discrepancy should be investigated by checking if the BME has been properly applied, and, in spite of the correct application of the BME, if the value identified show the actual non-fulfilment of the stakeholders' expectations.

If there are BME application inconsistencies, the application of the method should be repeated with the necessary corrections; if the values defined with the BME are still not satisfactory for the stakeholders, the party responsible for directing the BME process may propose an alternative benchmark by changing the minimum expectation expressed by the same during data collection; however, it is important that the defined benchmark be effectively achievable and does not represent an unreachable expectation that is detached from reality.

\subsubsection{Act (pre act and in act)}

This phase must be implemented under the direct responsibility of the PA that it has authority to activation of the processes of PPPN and which should have enabled the evaluation process through the BME. It can be divided in two sub-phases:

- Pre act, where guidelines, based on the benchmarks identified, must be prepared for use in subsequent programming inherent in the type of PPPN subjected to BME. The guidelines should be a set of recommendations developed in an organic and integrated and coordinated with each other, that recontextualise the benchmarks identified.

- In act, where the guidelines are approved and organised in a regulatory device thus making them 'protocol' and/or 'standard' and/or 'procedure" ${ }^{16}$ for the authority promoting the BME.

Thus, the guidelines formulated are an expression of behaviour and modus operandi shared by different PPPN stakeholders, and represent a starting point for subsequent planning regarding the type of process subjected to the BME, and may represent references to be followed during the validation phases (adoption and approval) of new initiatives.

\section{Application of the BME to the integrated action programmes (L.R. 22/1997) of the Lazio Region}

\subsection{Choice of the negotiation-type PPP on which to apply the BME: the integrated action programmes of the Lazio Region}

The intent of the trial was to test the validity and enforceability of the BME, with reference to the integrated action programmes (PII) initiated in the Lazio Region. The Lazio Region was chosen as an administrative-territorial setting due to the capability of accessing the regional archives of the Directorate for Territorial and Urban Development, which is entrusted with the activation of PPPN processes in the region ${ }^{17}$. The PII have been identified as the subject for the operational implementation of the BME, following a survey (conducted in 2012) of all urban planning tools implemented by the PPPN in Lazio between 1997 and 2011 (Table 7). 
Table 7 PPPN procedures initiated in the Lazio Region (2011)

\begin{tabular}{|c|c|c|c|c|c|}
\hline \multicolumn{2}{|l|}{ Tools } & \multicolumn{2}{|c|}{ Relevant legislation } & \multicolumn{2}{|c|}{ Procedures (at 2011) } \\
\hline Name & Acronym & National & Regional & Started & Approved \\
\hline $\begin{array}{l}\text { Integrated action } \\
\text { programmes }\end{array}$ & PII & L. 179/1992 & L.R. 22/1997 & 86 & $34^{*}$ \\
\hline $\begin{array}{l}\text { Programmes of urban } \\
\text { regenerations }\end{array}$ & PRU & L. $493 / 1993$ & L.R. 22/1997 & 24 & $13^{*}$ \\
\hline $\begin{array}{l}\text { Programmes of urban } \\
\text { riqualification }\end{array}$ & PRIU & L. 179/1992 & - & $0 * *$ & $0 * *$ \\
\hline $\begin{array}{l}\text { Programmes of urban } \\
\text { regeneration and sustainable } \\
\text { development of the territory }\end{array}$ & PRUSST & $\begin{array}{l}\text { D.M. } \\
\text { 08/10/1998 }\end{array}$ & - & 4 & $0 * * *$ \\
\hline Total & & - & & 114 & 47 \\
\hline $\begin{array}{l}\text { otes: *Indicative data: it ha } \\
\text { the DCR in order to v } \\
\text { **It was not possible } \\
\text { programs. This figure } \\
\text { ***The PRUSST con } \\
\text { have been approved, }\end{array}$ & $\begin{array}{l}t \text { been po } \\
y \text { the final } \\
\text { dentify pro } \\
\text { s not incl } \\
\text { of several } \\
\text { RUSST t }\end{array}$ & $\begin{array}{l}\text { le to consu } \\
\text { proval of th } \\
\text { sses specifi } \\
\text { the situati } \\
\text { tiatives: the } \\
11 \text { was col }\end{array}$ & $\begin{array}{l}\text { their entirety a } \\
\text { procedures co } \\
\text { lly related to } t \\
\text { of the Munici } \\
\text { fore although } \\
\text { oletely implem }\end{array}$ & $\begin{array}{l}\text { he DGR a } \\
\text { dered. } \\
\text { type of } \\
\text { ity of Ron } \\
\text { ne initiati } \\
\text { ted. }\end{array}$ & \\
\hline
\end{tabular}

This survey found that 114 PPPN initiatives have been activated in the Lazio region: $75.5 \%$ are PII (86); $21 \%$ PRU (24); 3.5\% PRUSST (4); no actions have been initiated with the PRIU instrument ${ }^{18}$. It is significant to emphasise that all of the 114 initiatives identified were presented as a variant to the PRG.

The BME was applied to the PII as the type of PPPN most commonly used (86 out of 114 total).

In line with the description provided in Section 3, having carried out the survey (2012) on the PPPN in Lazio, and identified the type of specific process (PII) for the experiment, the following phases were implemented:

- Plan

1 all initiatives related to the PII were analysed

2 a representative and 'homogeneous' sample was selected of approved PII (9), gathering all the elements (data inputs) necessary and significant to proceed with their examination as provided in the BME

3 categories of stakeholders were identified, for which it was necessary to detect the point of view in order to achieve shared results.

- Do

1 an impact matrix was built up, consisting of criteria, sub-criteria and viewpoint indicators, compiled using the data inputs collected on the representative sample of the PII considered

2 stakeholders analysis was implemented, distributing three specially prepared data sheets to a representative sample of subjects belonging to the identified categories of stakeholders, with the aim of detecting: 
a for each sub-criterion: the weight and objective functions (data sheet 1A), the level of satisfaction linked to performance (data sheet 1B)

b criteria for the selection of best in class PII (data sheet 3 )

3 a matrix of points of view was compiled using as input data the results of the calculations performed on the data shown in the data sheets $1 \mathrm{~A}$ and 2 during the interviews.

- Check

1 the data inputs inserted in the evaluation matrices (impacts and points of view) were processed in order to

2 obtain preference lists for each category of stakeholders, from which to identify the best in class PII, in accordance with the criteria specified in the stakeholders analysis

3 a summary framework was built for each sub-criterion outlining the performances of the best in class and subsequently, the values contained in each of these summary frameworks were developed to obtain an average and maximum value (relative to the performances) for each sub-criterion

4 the average and maximum values for performances were re-elaborated according to the points of view of the respondents involved in the stakeholders analysis; benchmarks were thus defined, adopting the average or maximum performance values, for which the majority of the categories of stakeholders expressed greater satisfaction

5 lastly, the benchmarks were checked for consistency with the PII regulatory standard.

- Act

This phase was not developed in this work since it falls specifically within the expertise of the regional PA, which, based on the benchmarks identified, will provide guidelines (pre-act) for programming/planning PII with standards and performances capable of generating sharing, satisfaction and consent for the PII processes involved, and which are higher compared to the situation considered at the time of application of the BME (2012). To this end, the general orientations will need to be implemented into guidelines/regulations (in-act).

\subsection{Plan}

\subsubsection{Analysis of the initiatives covered by the BME (PII)}

The PII were analysed, via direct consultation in the archives of the Lazio Region, of the documentation relative to the formative and authorisational procedural process (resolutions of the cabinet and/or municipal council, technical documentation, various opinions and authorisations, documents relating to service conferences where applicable). The information ${ }^{19}$ relating to each PII was processed and synthesised in relation to various ' $k$ ey ${ }^{20}$ aspects (Tables $8 \mathrm{a}, 8 \mathrm{~b}, 8 \mathrm{c}, 8 \mathrm{~d}$ ), allowing for the identification of the most significant PII initiatives: 
1 Procedural: by verifying

a the status of the procedure (whether completed or not)

b the year of definitive approval, if any

c the promoter (public, private, mixed PPP)

2 Urban: by verifying

a the size of the area of intervention (in hectares)

b the extent of regeneration (area of intervention, urban, municipal, supramunicipal); the condition of the intervention (active and/or discontinued functions)

3 Economic/financial: by verifying

a the presence/absence of extraordinary financial contributions

b public benefits stated in the PII proposals

4 Social: by verifying

a the categories of stakeholders involved in the process

b the population (number of households) potentially benefiting from the measures envisaged in the PII.

The analysis highlighted that:

1 the majority of proposals (66) are of a private nature; only 18 are public-private initiatives, and two are public

2 almost all PII initiatives regard areas ranging in size between one and five hectares

3 all PII provide for actions that are local and/or municipal; no PII includes any intervention that can have a significant affect on a supra-municipal scale

422 PII were proposed in areas devoid of any function; 48 PII regard urban areas that are already settled, but mostly only 16 PII provide for the transformation of urban areas and brownfield sites

5 all PII projects describe collective benefits, without quantifying them

684 PII projects provide for an extraordinary urbanisation contribution (in addition to the costs required by law) for the construction of public works

7 there are always three categories of stakeholders involved: municipal PA, regional PA, entrepreneurs; the involvement of the local population and citizens' associations is absent

8 the number of households benefiting from the interventions was estimated ${ }^{21}:$ in 55 cases out of 86 , less than 10 ; in 25 cases out of 86 , between 10 and 50 ; only in six cases at more than 50 . 
Table 8a Analysis of PII in Lazio: procedural aspects (excerpt)

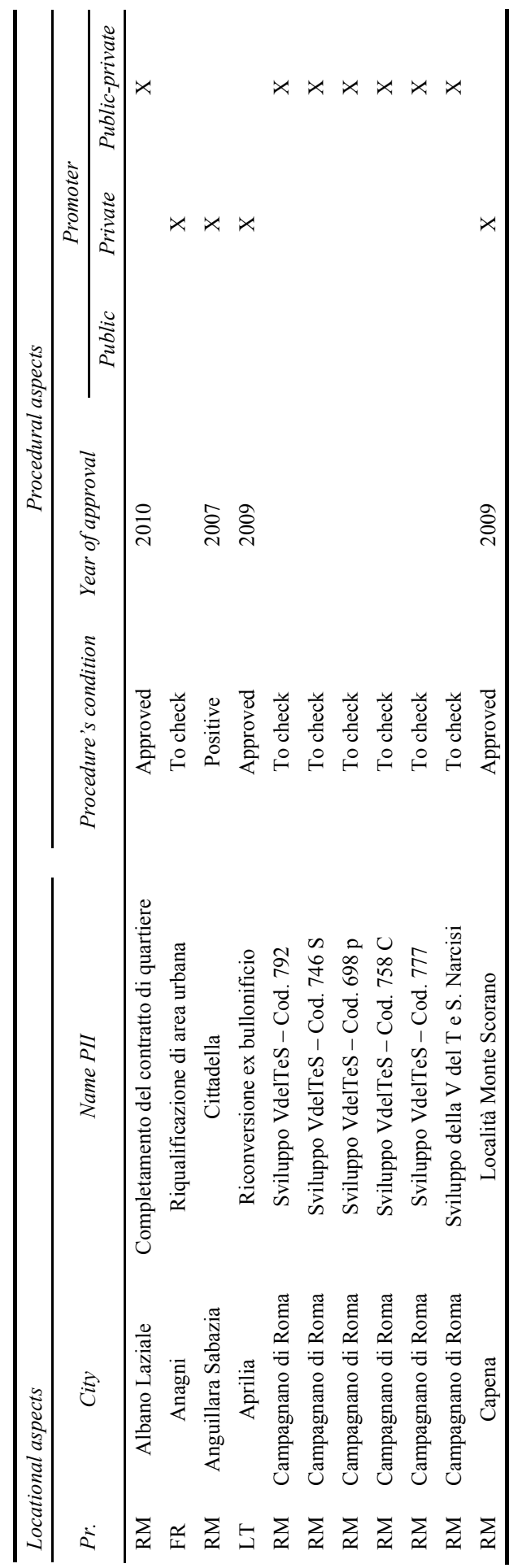


Table 8b Analysis of PII in Lazio: urban aspects (excerpt)

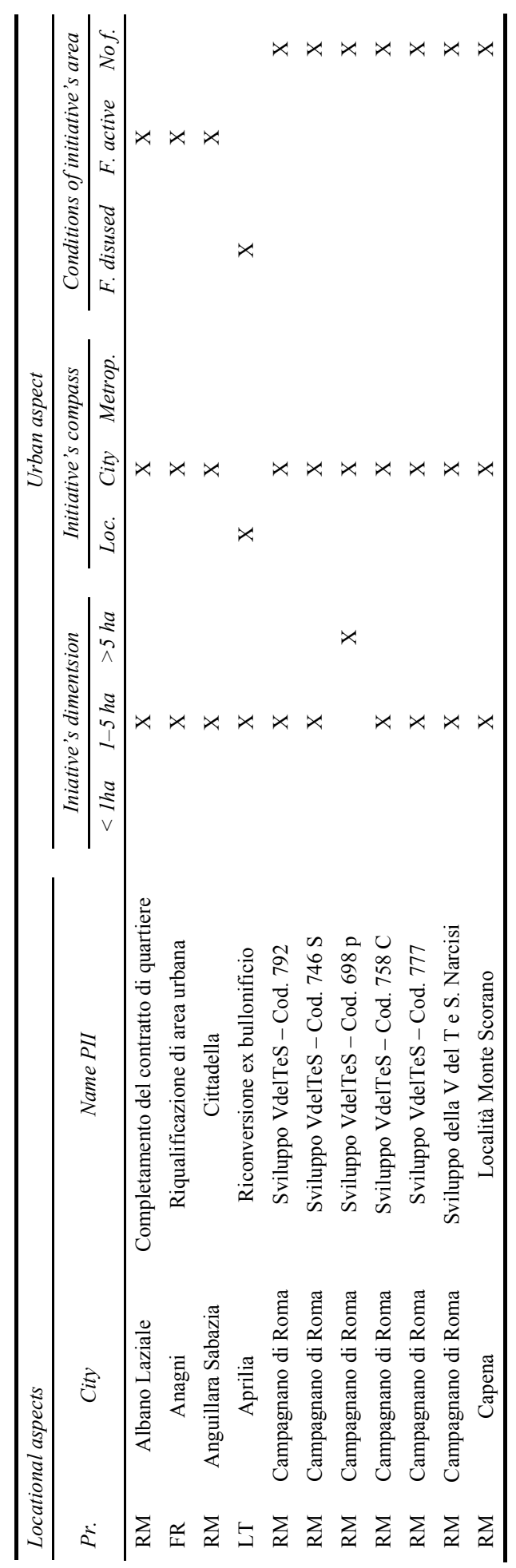


Table 8c Analysis of PII in Lazio: financial aspects (excerpt)

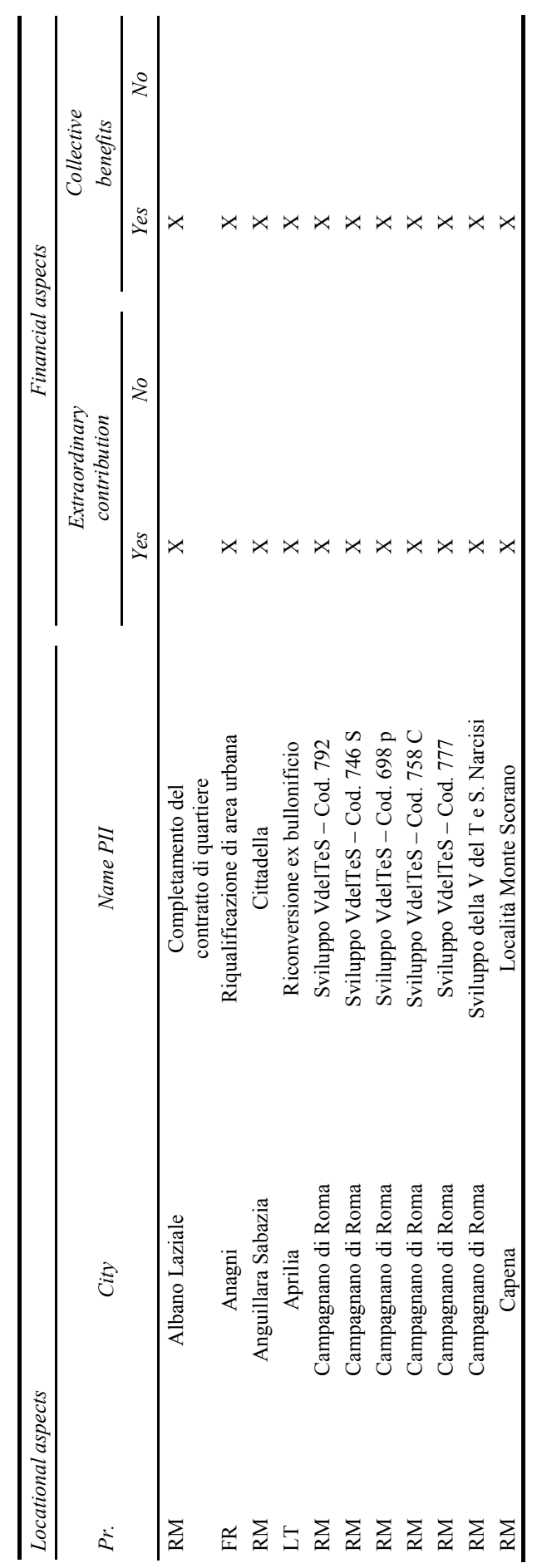


Table 8d Analysis of PII in Lazio: social aspects (excerpt)

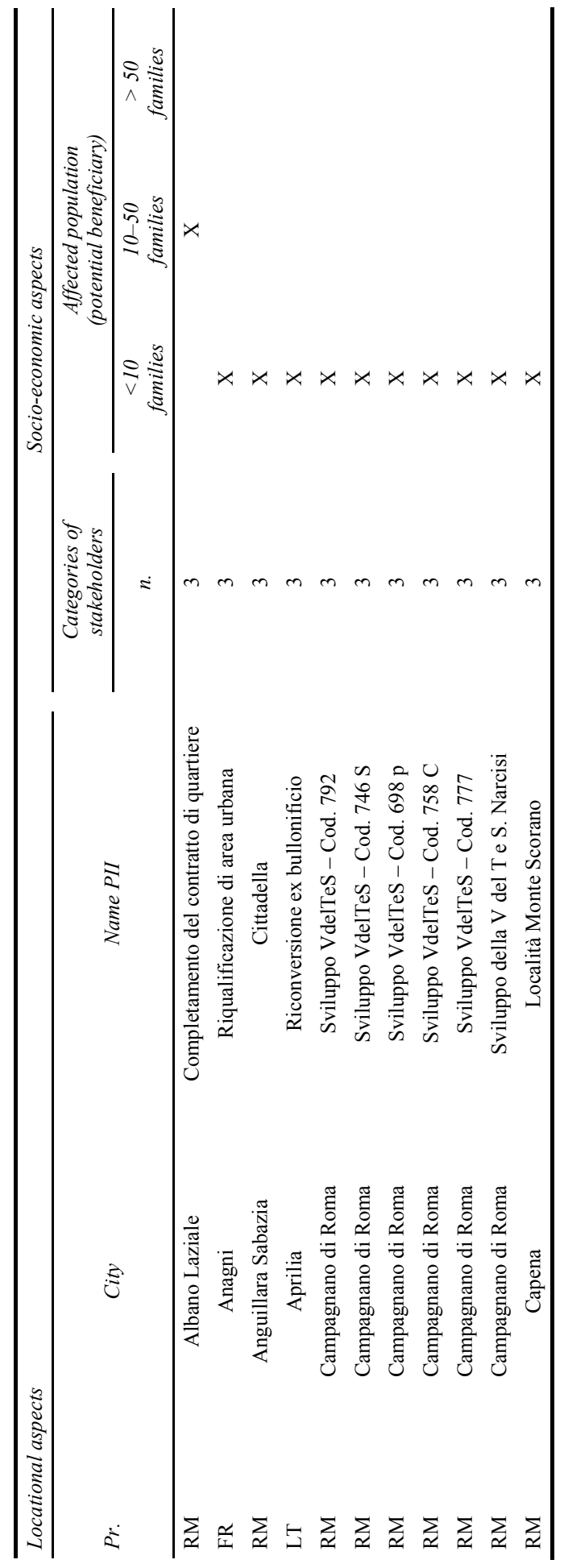




\subsubsection{Identification and analysis of the representative sample of PII}

In order to implement the BME in a lean and efficient manner, given the large number of initiatives (PII) initiated in the Lazio Region between 1997 and 2011, it was necessary to select a representative and comparable sample of PII initiatives (Table 9). The sample of nine PII initiatives on which the evaluation focuses was selected on the basis of three criteria:

1 approval as recent as possible (three-year period from 2009-2011)

2 PII estimates whose overall scope was at least municipal in scale

3 the possibility of obtaining full documentation for the purposes of the BME.

Table 9 PII initiatives selected for testing

\begin{tabular}{lcccc}
\hline Pr. & City & Name PII & $\begin{array}{c}\text { Procedure's } \\
\text { condition }\end{array}$ & Year of approval \\
\hline LT & Aprilia & Ex bullonificio & $\begin{array}{c}\text { Approved with } \\
\text { prescriptions }\end{array}$ & 2009 \\
RM & Capena & Monte Scorano & Approved & 2009 \\
FR & Cassino & Via Vagni & Approved & 2009 \\
RM & Castel Madama & Frainili & $\begin{array}{c}\text { Positive with } \\
\text { prescriptions }\end{array}$ & 2009 \\
RM & Grottaferrata & Grand Hotel & Positive with & 2010 \\
RM & Ladispoli & Traiano & prescriptions & \\
RM & Mentana & Il Faro & Approved & 2009 \\
RM & Mentana & Santa droce & Approved & 2009 \\
RM & Monterotondo & Dogana & Approved & 2009 \\
\hline
\end{tabular}

A data sheet (Table 10) was then drawn up for each of the nine (alternatives) 'sample' PII, summarising the primary data concerning the general aspects, as well as procedural, planning, financial and socio-economic factors.

Table 10 Data sheet of the PII initiatives selected for testing (example for one PII)

\begin{tabular}{llc}
\hline $\begin{array}{l}\text { General and } \\
\text { procedural }\end{array}$ & Programme name & Ex bullonificio \\
aspects & Region & Lazio \\
& Province & Roma \\
& City & Aprilia \\
& Resident population to 2011 & 71.150 \\
& Area & City center - Via Monteverdi \\
& Promoter & Private \\
Stakeholders & Local PA - Private promoter \\
& Procedure's condition & Approved in 2010 \\
& Implementation time (months) & 48 \\
\hline
\end{tabular}


Table 10 Data sheet of the PII initiatives selected for testing (example for one PII) (continued)

\begin{tabular}{|c|c|c|c|c|}
\hline \multirow{19}{*}{$\begin{array}{l}\text { Urban } \\
\text { aspects }\end{array}$} & Dimension of initiative & sq. m. & 19.640 & total \\
\hline & Private building potential ante PII & cu. m. & 28.000 & Productive \\
\hline & & cu. m. & 28.000 & Total \\
\hline & Private building potential post PII & cu. m. & 33.670 & Residential \\
\hline & & cu. m. & 10.256 & $\begin{array}{l}\text { Commercial } \\
\text { and directional }\end{array}$ \\
\hline & & cu. m. & 43.926 & Total \\
\hline & $\begin{array}{l}\text { Difference ante and post PII } \\
\text { private building potential }\end{array}$ & cu. m. & 15.926 & Total \\
\hline & Private buildings to be demolished & cu. m. & 28.000 & Total \\
\hline & Public buildings to be built & cu. m. & 7.292 & Total \\
\hline & Public buildings to be redeveloped & cu. m. & 0 & Total \\
\hline & & & $\begin{array}{c}\text { Requirements } \\
\text { of PII }\end{array}$ & $\begin{array}{c}\text { Municipal } \\
\text { requirements } \\
\text { prior }\end{array}$ \\
\hline & Public green areas & sq. m. & 2.706 & 0 \\
\hline & Equipped & $s q . m$ & 0 & 0 \\
\hline & Non-equipped & $s q . m$ & 2.706 & 0 \\
\hline & Public parking area & sq. m. & 2.425 & 0 \\
\hline & Public services area & sq. m. & 4.880 & 0 \\
\hline & Aree destinate a viabilità & sq. m. & 4.612 & 0 \\
\hline & Total public area & sq. m. & 14.623 & 0 \\
\hline & $\begin{array}{l}\text { Average age of buildings } \\
\text { included in the PII }\end{array}$ & Years & \multicolumn{2}{|c|}{50} \\
\hline \multirow[t]{6}{*}{$\begin{array}{l}\text { Financial } \\
\text { aspects }\end{array}$} & $\begin{array}{l}\text { Financial benefit to the } \\
\text { promoter generated by PII }\end{array}$ & $€$ & \multicolumn{2}{|c|}{7.657 .200} \\
\hline & Extraordinary contribution & $€$ & \multicolumn{2}{|c|}{1.255 .674} \\
\hline & $\begin{array}{l}\text { Ordinary expenses (opere di } \\
\text { urbanizzazione e concessori) }\end{array}$ & $€$ & \multicolumn{2}{|c|}{1.625 .927} \\
\hline & Financial benefit to the PA & $€$ & \multicolumn{2}{|c|}{2.881 .601} \\
\hline & $\begin{array}{l}\text { Public funding in favour } \\
\text { of the private proponent }\end{array}$ & $€$ & \multicolumn{2}{|c|}{0} \\
\hline & Social housing & $€$ & \multicolumn{2}{|c|}{0} \\
\hline \multirow{2}{*}{$\begin{array}{l}\text { Socio- } \\
\text { economic } \\
\text { aspects }\end{array}$} & Permanent employment & Employees & \multicolumn{2}{|c|}{61} \\
\hline & $\begin{array}{l}\text { Temporary employment } \\
\text { (constructor sector) }\end{array}$ & $\begin{array}{l}\text { Employees } \\
\text { (one year) }\end{array}$ & \multicolumn{2}{|c|}{598} \\
\hline
\end{tabular}

\subsubsection{Selection of stakeholder categories}

In keeping with the means of identifying the categories of stakeholders (see Section 3.3, Plan), and based on the results of the analysis relating to the PII, it was deemed necessary to consider as stakeholders: 
- regional PA (D. Territorial), i.e., subjects classified as technical personnel in the Directorate for Territorial and Urban Development of the Lazio Region, and/or employees of the Council for Urban Planning of the Lazio Region, and/or the regional council

- local PA, i.e., subjects classified as municipal administrations and/or political representatives in office in these PA

- $\quad$ private promoters (entrepreneurs): directors/members of business groups actively involved in the Lazio Region

- $\quad$ population: subjects pertaining to neighbourhood committees, non-profit organisations for the defence of citizens' rights, and a random sample of citizens.

\subsection{Do}

\subsubsection{Building the impact matrix}

The building of the impact matrix firstly required the formulation of sub-criteria and related indicators referring to the criteria adopted in the BME (see par. 3.3 Do). The sub-criteria were formulated by examining several case studies ${ }^{22}$ related to evaluations conducted on PPPN in Italy, as well as on the basis of available data on the PII considered, taking into account both their significance, and the possibility of measuring the relative indicators. In the case studies examined, the number of criteria was comprised between 25 and 40; 35 sub-criteria were defined with related indicators (Table 11).

Sub-criteria were distributed as follows:

- $\quad$ eight sub-criteria and related financial indicators derived from an analysis of technical reports, adopted PPPN resolutions primarily related to the economic and financial content which emerged in the consultation (Morano and Tajani, 2014a)

- three sub-criteria and related procedural indicators derived from an analysis of the legislation/regulations relating to PII, and in particular to Law 179/92, L.R. Lazio 22/97 and subsequent amendments, as well as the green paper on PPP by the European Commission

- six sub-criteria and related socio-economic indicators taking into account the economic and social development aspects considered in the planning documents of a sampling of local government administrations in Lazio, including the resolutions for the adoption and approval of the PRG, PUCG, Provincial Plan of Rome and Provincial Plan of Viterbo

- three sub-criteria ${ }^{23}$ and related environmental indicators, allowing solely for the evaluation of the programme's macro effects on the environment

- 15 sub-criteria and related urban planning indicators in relation to the requirements of the implementation plans for the legislation/planning regulations in force (national and regional). 
Table 11 Criteria, sub-criteria and indicators for the testing

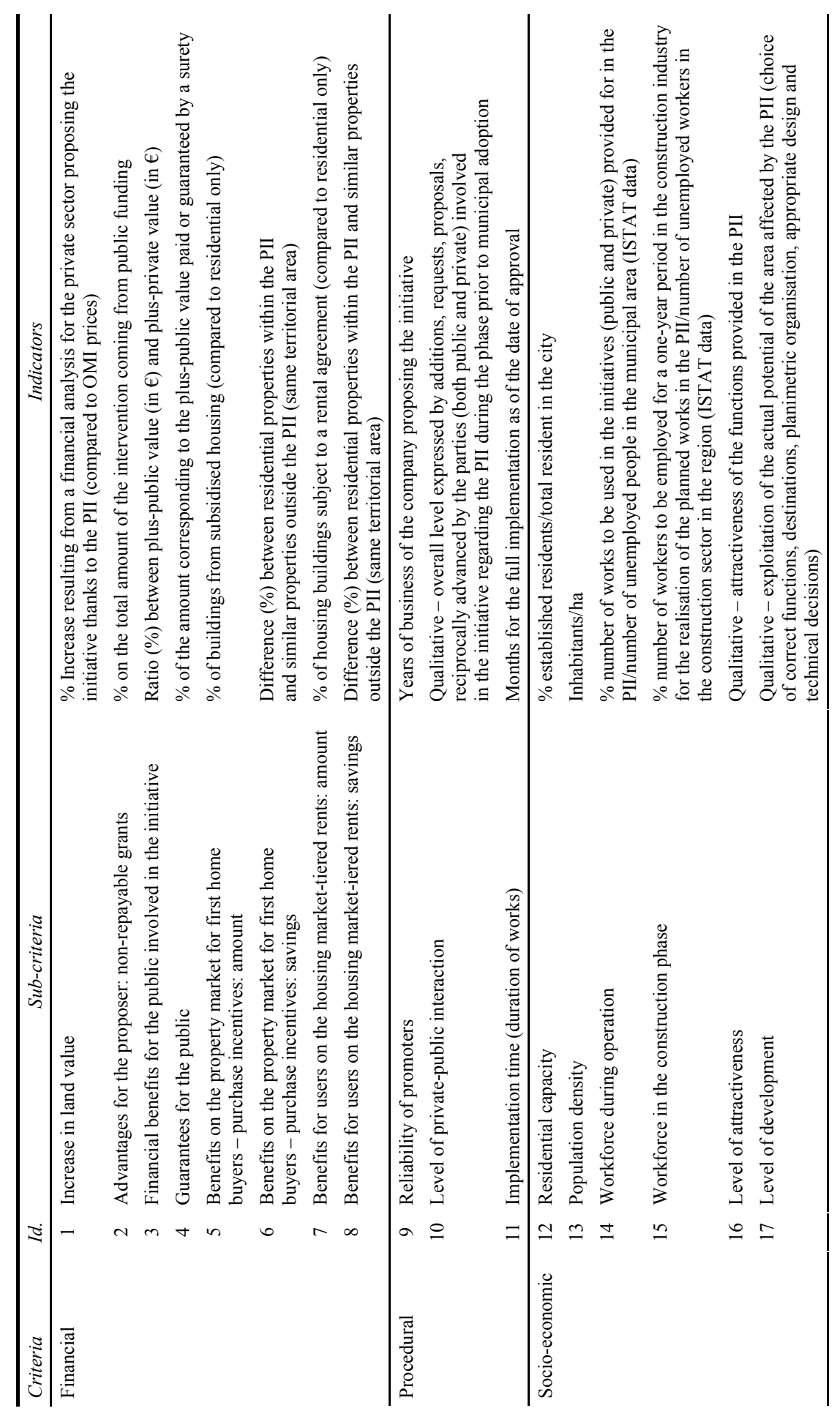


Table 11 Criteria, sub-criteria and indicators for the testing

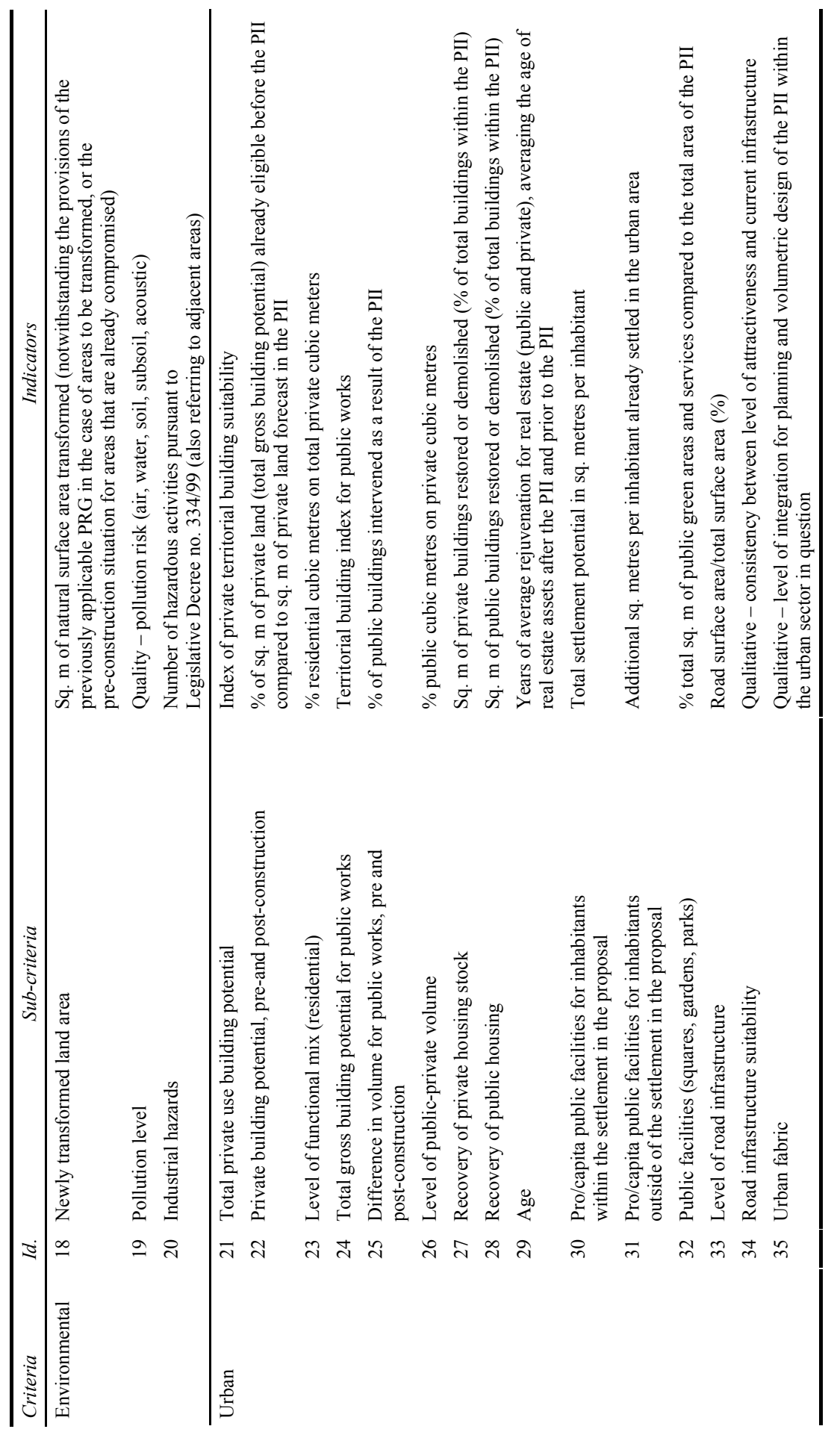


Table 12 Impact matrix

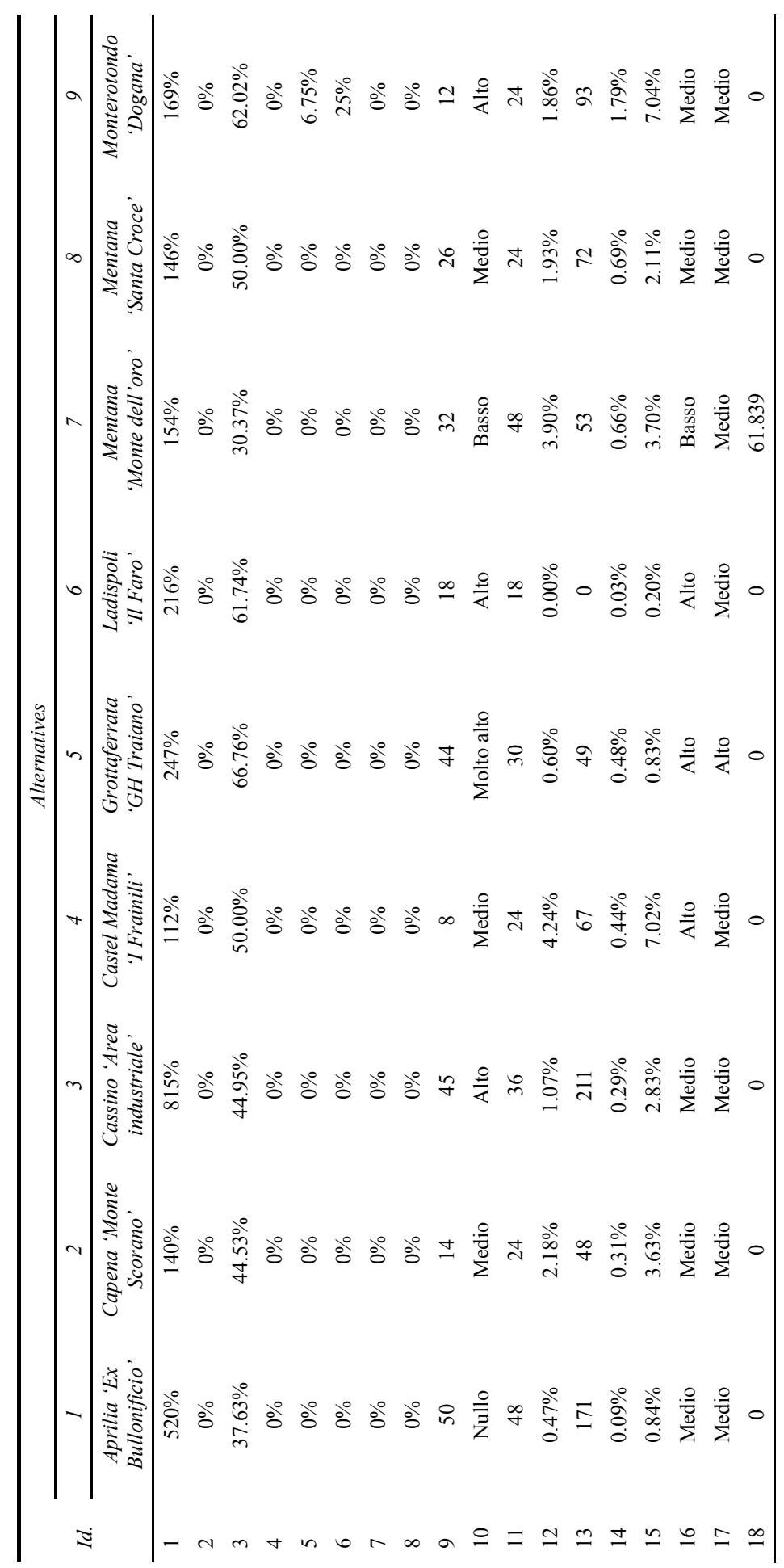


Table 12 Impact matrix (continued)

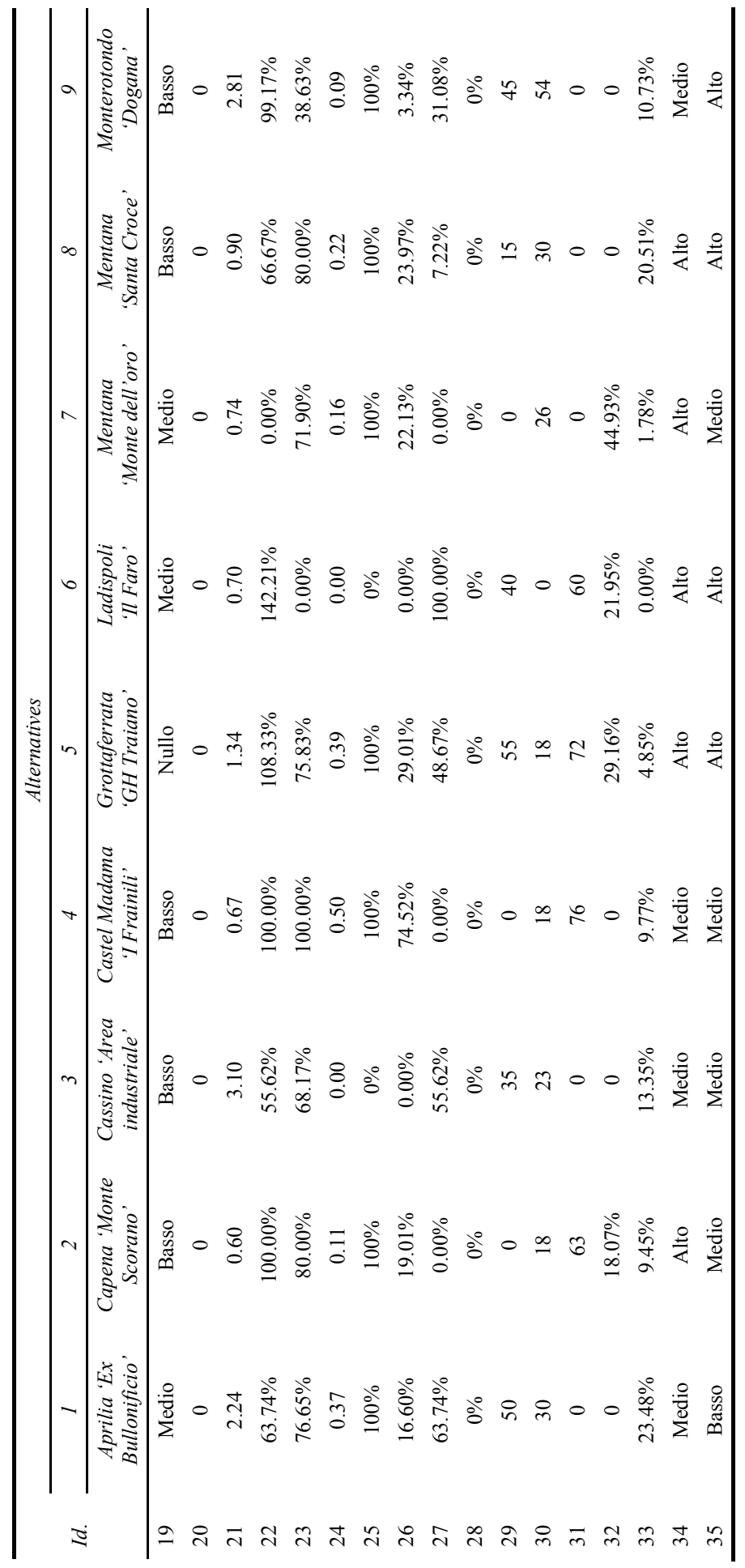


With reference to nine 'sample' (alternative) PII, the impact matrix (Table 12) was compiled with the data inputs deduced and/or processed based on the information provided in the data sheets of each PII considered.

\subsubsection{Implementation of the stakeholder analysis}

The purpose of the stakeholders analysis is to detect directly from the subjects belonging to the categories of stakeholders identified, the cognitive elements for building the viewpoints matrix, as well as to develop the subsequent check phase. The stakeholders analysis was implemented by providing three inquiry data sheets, submitted to the interview subjects (and subsequently interviewed), aimed at:

- detecting:

a the objective functions for each indicator (data sheet 1A); each respondent indicated the orientation of the performance trends, choosing one of three possible orientations of the same objective function (referring to performance)

1 maximisation (tendency towards a maximum)

2 minimisation (tendency toward a minimum)

3 identification of a range of values

b the threshold of satisfaction for the values of the sub-criteria indicators (data sheet 1B): for each sub-criterion, each respondent expressed satisfaction (very high, high, medium, low) for the value of the indicator

- weighing the criteria and sub-criteria (data sheet 2): each respondent assigned a weight to each sub-criterion based on 100

- defining the best in class selection procedures (data sheet 3): each respondent expressed an opinion regarding the criteria for selecting the best in class.

The data sheets were compiled by interviewing a sample of 108 individuals $^{24}$ representative of the different categories of stakeholders identified: 19 subjects pertaining to the regional PA; 24 subjects belonging to the local PA; nine subjects pertaining to entrepreneurs, and 50 subjects belonging to the population.

The data collected through the interviews was interpolated in order to reach a representative summary of the viewpoints of each category of stakeholders.

In particular, the evaluation of the data contained in the inquiry data sheets:

- data sheets $1 \mathrm{~A}$ and 2 provided a summary of opinions to be entered in the viewpoints matrix (Table 13)

- data sheet $1 \mathrm{~B}$ provided a summary of opinions representing the level of satisfaction of the categories of stakeholders in relation to the values of the indicator for each sub-criterion used in the check phase to verify the level of satisfaction of the average and maximum values relating to performance for best in class (see below par.

Section 4.3 and Table 16)

- data sheet 3 criteria were obtained to identify the best in class among the nine PII initiatives considered (see below par. Section 4.3.2 and Table 14). 
Table 13 Viewpoints matrix

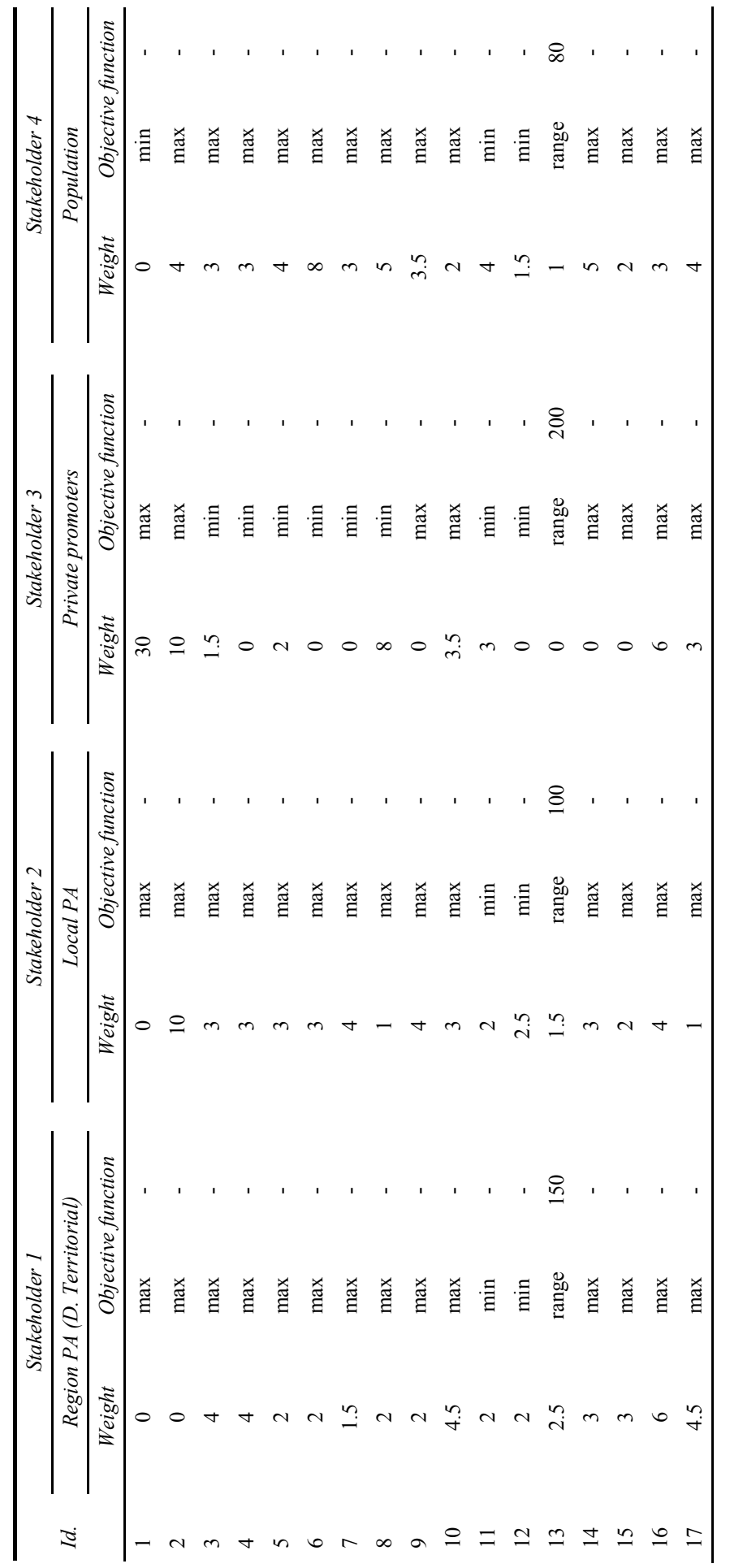


Table 13 Viewpoints matrix (continued)

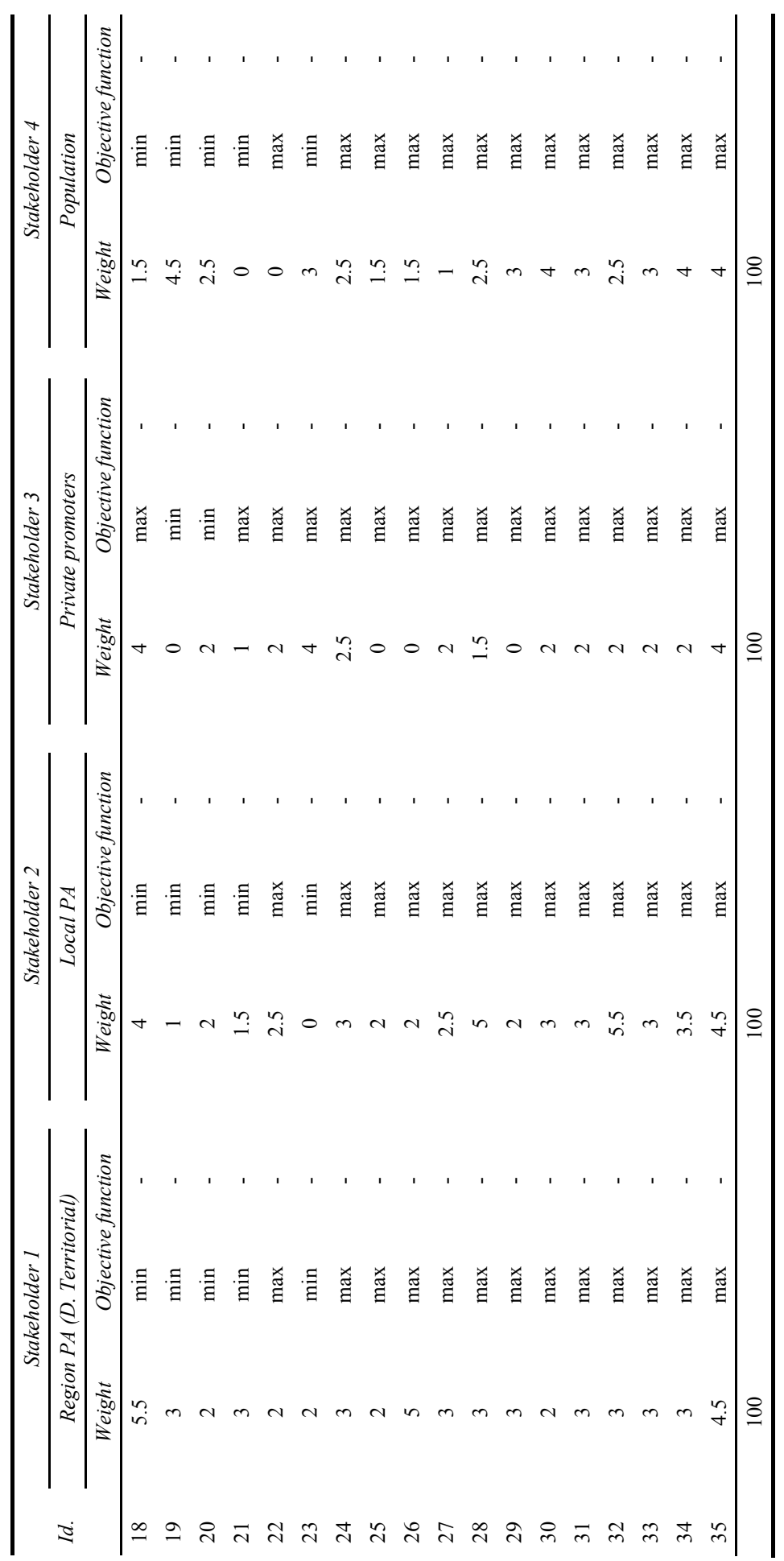




\subsubsection{Building the viewpoints matrix}

As noted above, the viewpoints matrix (Table 13) was compiled using the data obtained in a survey data sheets $1 \mathrm{~A}$ and 2 .

For each sub-criterion, it contains a summary attributable to each class of stakeholders relating to:

1 weight, obtained by the arithmetic mean of the weights indicated in the interviews of all subjects belonging to a specific category of stakeholders

2 the objective function, chosen according to the greater number of preferences expressed by respondents for the three possible trends of the objective functions ${ }^{25}$.

\subsection{Check}

\subsubsection{Processing the input data (aggregation of viewpoints) through an AHP}

Consistent with the procedure laid down in the BME, in relation to the characteristics for the application (number of alternatives, sub-criteria and subjects involved, recognition in the Italian legal system, qualitative and quantitative data, quantitative difference between the elements of the evaluation, need for the shortest possible time frames), the procedure chosen for processing the data inputs contained in the impact viewpoints matrices (aggregation of viewpoints) (Morano et al., 2014) was the analytic hierarchy process (AHP), implemented with the aid of the software Expert Choice ${ }^{26}$.

\subsubsection{Ranking (single-group) for categories of stakeholders and definition of best in class}

By aggregating the opinions expressed, it was possible to obtain, for each category of stakeholders, an order of preference (single-group ranking) for the nine alternatives taken into consideration (Table 14). Subsequently, the best in class were defined, i.e. the alternatives to be adopted as 'references' for the definition of benchmarks.

A reading the single-group rankings highlights how three categories of stakeholders (regional, local authorities and population) have a substantial share in relation to 'best' alternatives. The ranking of entrepreneurs expresses a viewpoint that differs significantly, since this group is primarily concerned with private interests; as such, two alternatives in the top positions of the entrepreneurs ranking are in last positions for the regional, local authorities and population.

The best in class i.e., alternatives, which according to the shared opinion of the stakeholders can be taken into account for the identification of benchmarks, were identified using the results compiled from data sheet 3 in the stakeholders analysis.

An examination of the responses provided by the subjects interviewed in data sheet 3 showed that: the majority of respondents believe that they can rate as best in class the first five alternatives set out in the rankings ( 47 preferences out of 108 respondents), as long as they are present in at least three out of rankings (58 preferences out of 108 respondents).

Based on these results, the selected best in class are highlighted in grey in Table 14. 
Table 14 Comparison of stakeholder rankings and definition of best in class (in grey)

\begin{tabular}{lcccc}
\hline & $\begin{array}{c}\text { Region PA } \\
\text { (D. Territorial) }\end{array}$ & Local PA & $\begin{array}{c}\text { Private } \\
\text { promoters }\end{array}$ & Population \\
\cline { 2 - 5 } & Pos. & Pos. & Pos. & Pos. \\
\hline Aprilia 'Ex Bullonificio' & 6 & 7 & 2 & 6 \\
Capena 'Monte Scorano' & 7 & 6 & 7 & 7 \\
Cassino 'Area industriale' & 8 & 8 & 1 & 9 \\
Castel Madama 'I Frainili' & 1 & 3 & 5 & 3 \\
Grottaferrata 'GH Traiano' & 2 & 1 & 3 & 2 \\
Ladispoli 'Il Faro' & 4 & 4 & 4 & 4 \\
\hline Mentana 'Monte dell'oro' & 9 & 9 & 8 & 8 \\
Mentana 'Santa Croce' & 5 & 5 & 6 & 5 \\
Monterotondo 'Dogana' & 3 & 2 & 9 & 1 \\
\hline
\end{tabular}

\subsubsection{Building summary frameworks for each sub-criterion, and definition of average and maximum performance (pre-benchmark range)}

Having selected the best in class PII, a summary framework was compiled for each subcriterion considered in the evaluation of the PII initiatives (Figure 1), which contains the performances of the best in class, both in a numerical format and set in graphic form on histograms, providing a more immediate comparison between the performances of the nine PII.

Figure 1 Summary framework (e.g., sub-criterion no. 1 - increase in land value)

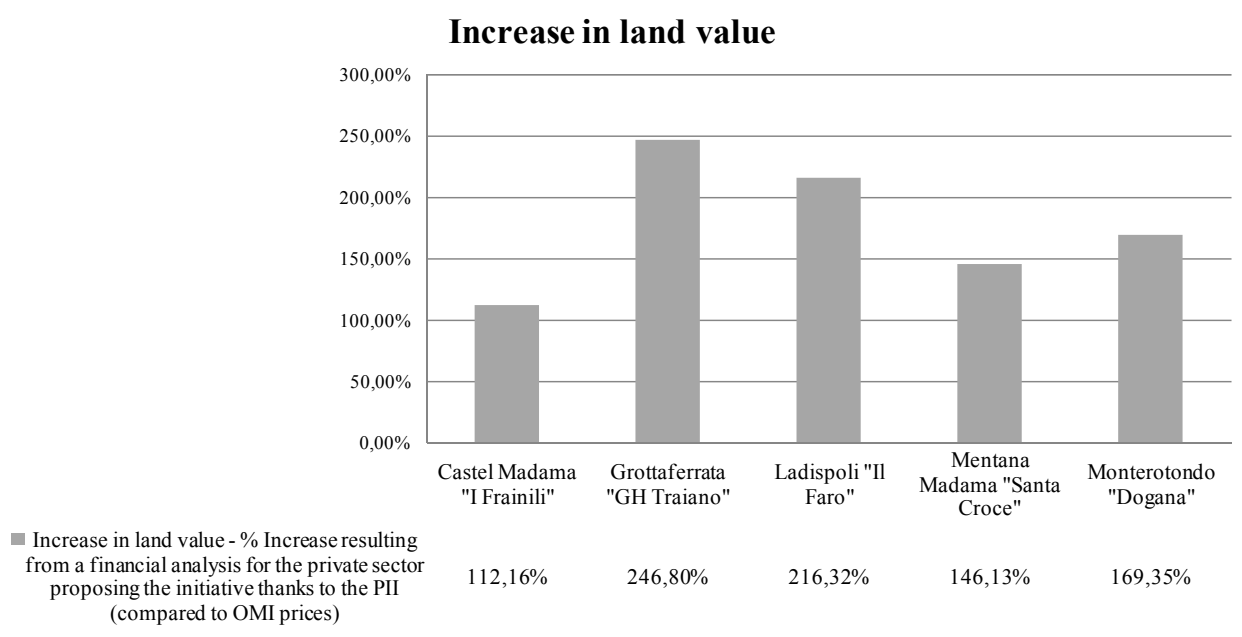


Table 15 Average and maximum values for the best in class

\begin{tabular}{|c|c|c|c|}
\hline \multirow[b]{2}{*}{ Criteria } & \multirow{2}{*}{$\begin{array}{c}I d . \\
\text { sub-criteria }\end{array}$} & \multicolumn{2}{|c|}{ Best in class } \\
\hline & & Average value & $\begin{array}{c}\text { Maximum value } \\
\text { (prevailint objective function) }\end{array}$ \\
\hline \multirow[t]{8}{*}{ Financial } & 1 & $178.15 \%$ & $246.80 \%$ \\
\hline & 2 & $0.00 \%$ & $0.00 \%$ \\
\hline & 3 & $58.10 \%$ & $66.76 \%$ \\
\hline & 4 & $0.00 \%$ & $0.00 \%$ \\
\hline & 5 & $1.35 \%$ & $6.75 \%$ \\
\hline & 6 & $5.00 \%$ & $25.00 \%$ \\
\hline & 7 & $0.00 \%$ & $0.00 \%$ \\
\hline & 8 & $0.00 \%$ & $0.00 \%$ \\
\hline \multirow[t]{3}{*}{ Procedural } & 9 & 21.6 & 44 \\
\hline & 10 & High & Very high \\
\hline & 11 & 24 & 18 \\
\hline \multirow[t]{6}{*}{ Socio-economic } & 12 & $1.73 \%$ & $0.00 \%$ \\
\hline & 13 & 56 & 93 \\
\hline & 14 & $0.68 \%$ & $1.79 \%$ \\
\hline & 15 & $3.01 \%$ & $7.04 \%$ \\
\hline & 16 & High & High \\
\hline & 17 & Medium & High \\
\hline \multirow[t]{3}{*}{ Environmental } & 18 & 0 & 0 \\
\hline & 19 & Low & Null \\
\hline & 20 & 0 & 0 \\
\hline \multirow[t]{15}{*}{ Urban } & 21 & 1.29 & 0.67 \\
\hline & 22 & $103.27 \%$ & $142.21 \%$ \\
\hline & 23 & $58.89 \%$ & $0.00 \%$ \\
\hline & 24 & 0.24 & 0.50 \\
\hline & 25 & $80.00 \%$ & $100.00 \%$ \\
\hline & 26 & $26.17 \%$ & $74.52 \%$ \\
\hline & 27 & $37.39 \%$ & $100.00 \%$ \\
\hline & 28 & 0 & 0 \\
\hline & 29 & 31 & 55 \\
\hline & 30 & 24.06 & 53.81 \\
\hline & 31 & 41.60 & 76.00 \\
\hline & 32 & $11.64 \%$ & $29.16 \%$ \\
\hline & 33 & $9.17 \%$ & $20.51 \%$ \\
\hline & 34 & High & High \\
\hline & 35 & High & High \\
\hline
\end{tabular}


The performance data contained in the summary frameworks were further developed in order to define (Table 15) for each sub-criterion:

- the maximum value representing the best performance detected for the best in class PII initiatives, expressed in relation to the prevailing objective function (for the different categories of stakeholders) ${ }^{27}$

- the average value of the performances for the best in class.

The maximum and average of the best in class PII define the range within which the benchmarks can appropriately be determined.

\subsubsection{Verifying the level of satisfaction of stakeholders on the pre-benchmark range (average and maximum values for best in class), and definition of benchmarks}

The assessment of the level of satisfaction expressed by stakeholders for the average and maximum values relating to performance for the best in class (for each sub-criterion) was performed (Table 16) by comparing, for each sub-criterion, the average and maximum values for the best in class with the data on the level of satisfaction expressed by the stakeholders, emerging from the data collected in the point 1B of the stakeholders analysis (see Section 4.3.2).

For each sub-criterion, the benchmarks were formulated (Table 17) in relation to the concordance/discordance of the level of satisfaction expressed by the various categories of stakeholders, choosing the value for which a level of satisfaction was found for at least three categories of stakeholders out of 4 (for the requirement's equal acceptability, the value was chosen for which the greatest satisfaction was expressed). Where this requirement was not found (sub-criteria no. 2, 4, 7 and 8), the benchmark was identified as a function of the level of satisfaction of on average at least two stakeholders out of four.

The benchmarks thus determined, are representative of the performances already achieved ${ }^{28}$ in the best five PII initiatives (among the nine considered) that are approved and in force. The benchmarks represent possible proposals for 'changes' and 'improvements' to PII initiatives, which, if validated by the PA, can be adopted and implemented in the future planning and verification of similar instruments.

Having defined the benchmarks, their consistency was verified with the regulatory standards for PII initiatives in the Lazio Region (L.R. 22/1997). The findings showed that:

- 32 benchmarks out of 35 express particularly significant data, capable of providing useful elements for defining operational guidelines towards initiating a new programming phase for the PII instrument

- three benchmarks out of 35 fail to provide any useful content for the definition of guidelines for the instrument.

The results of the application are thus consistent overall. 
Table 16 Approval of stakeholders on the average/maximum values for best in class PII

\begin{tabular}{|c|c|}
\hline 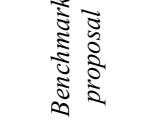 & 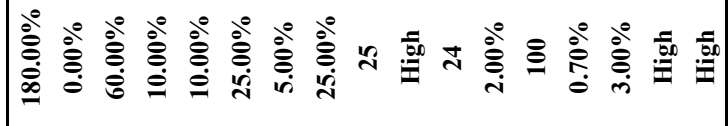 \\
\hline$\Omega^{\circ}$ & 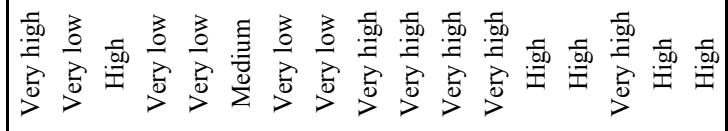 \\
\hline 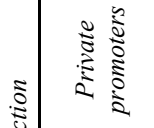 & 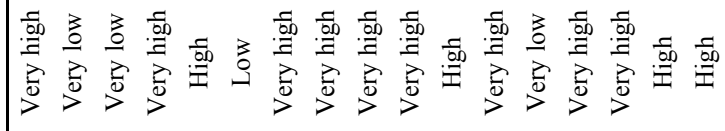 \\
\hline ๘ & 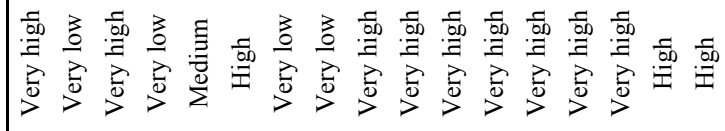 \\
\hline 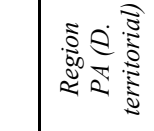 & 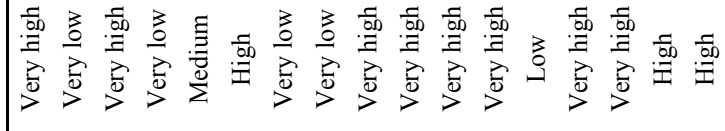 \\
\hline 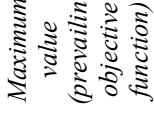 & 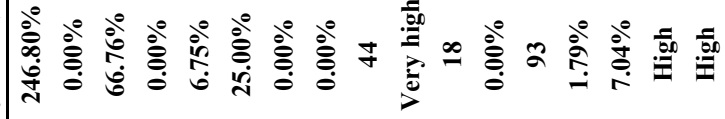 \\
\hline 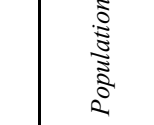 & 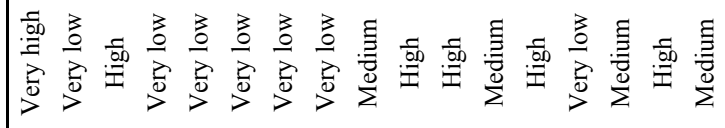 \\
\hline 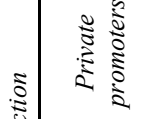 & 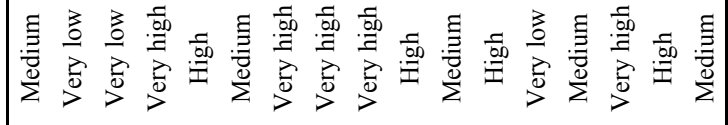 \\
\hline 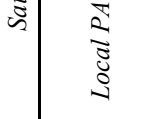 & 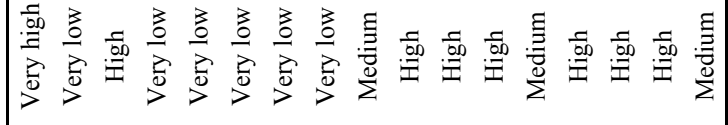 \\
\hline 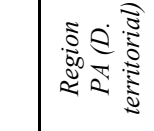 & 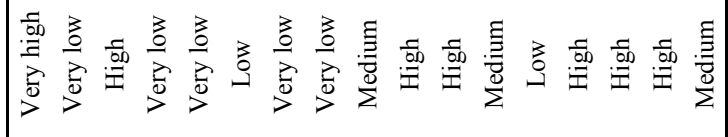 \\
\hline 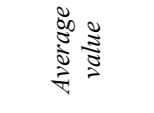 & 总 \\
\hline 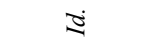 & $\alpha m+n b r \infty a$ 电 \\
\hline
\end{tabular}


Table 16 Approval of stakeholders on the average/maximum values for best in class PII (continued)

\begin{tabular}{|c|c|}
\hline 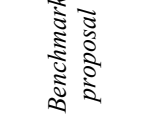 & 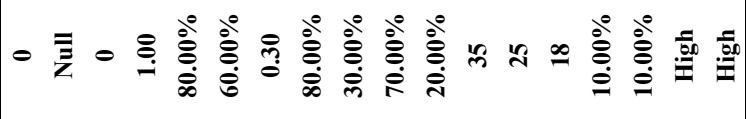 \\
\hline & 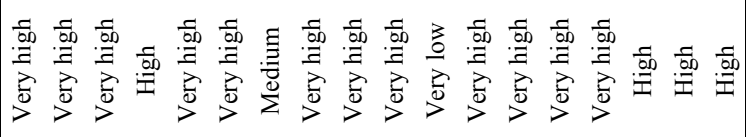 \\
\hline ह & 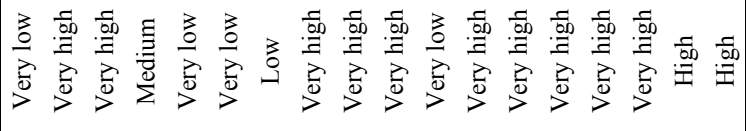 \\
\hline$\Sigma$ & 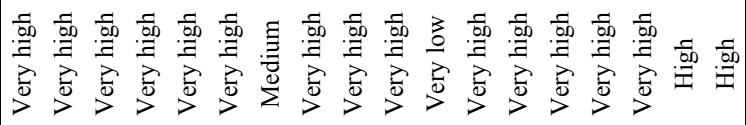 \\
\hline 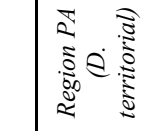 & 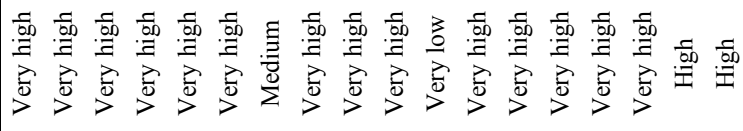 \\
\hline 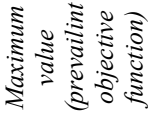 & 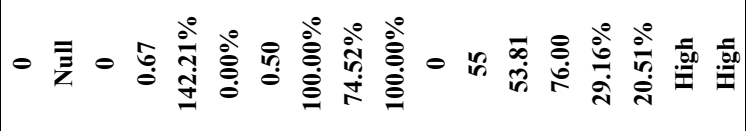 \\
\hline 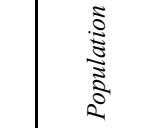 & 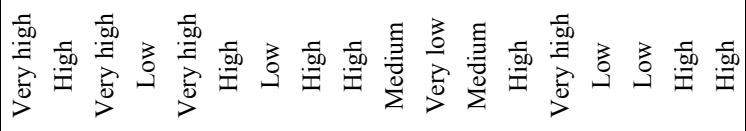 \\
\hline 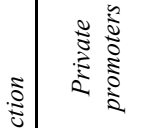 & 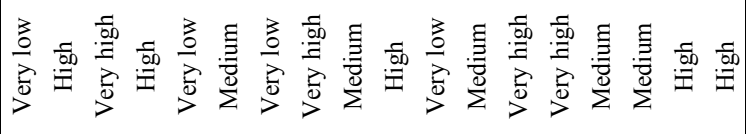 \\
\hline$\stackrel{్}{\mathscr{S}}$ & 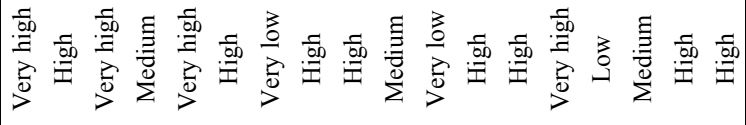 \\
\hline 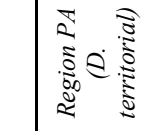 & 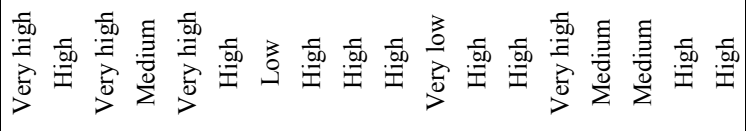 \\
\hline 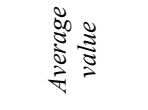 & 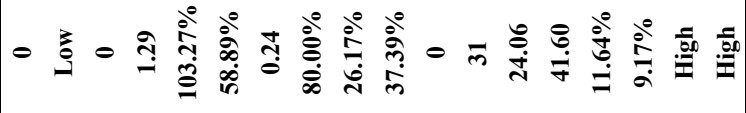 \\
\hline$\geqq$ & 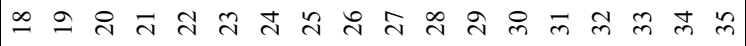 \\
\hline
\end{tabular}


Table 17 Summary of benchmarks for each sub-criterion/indicator

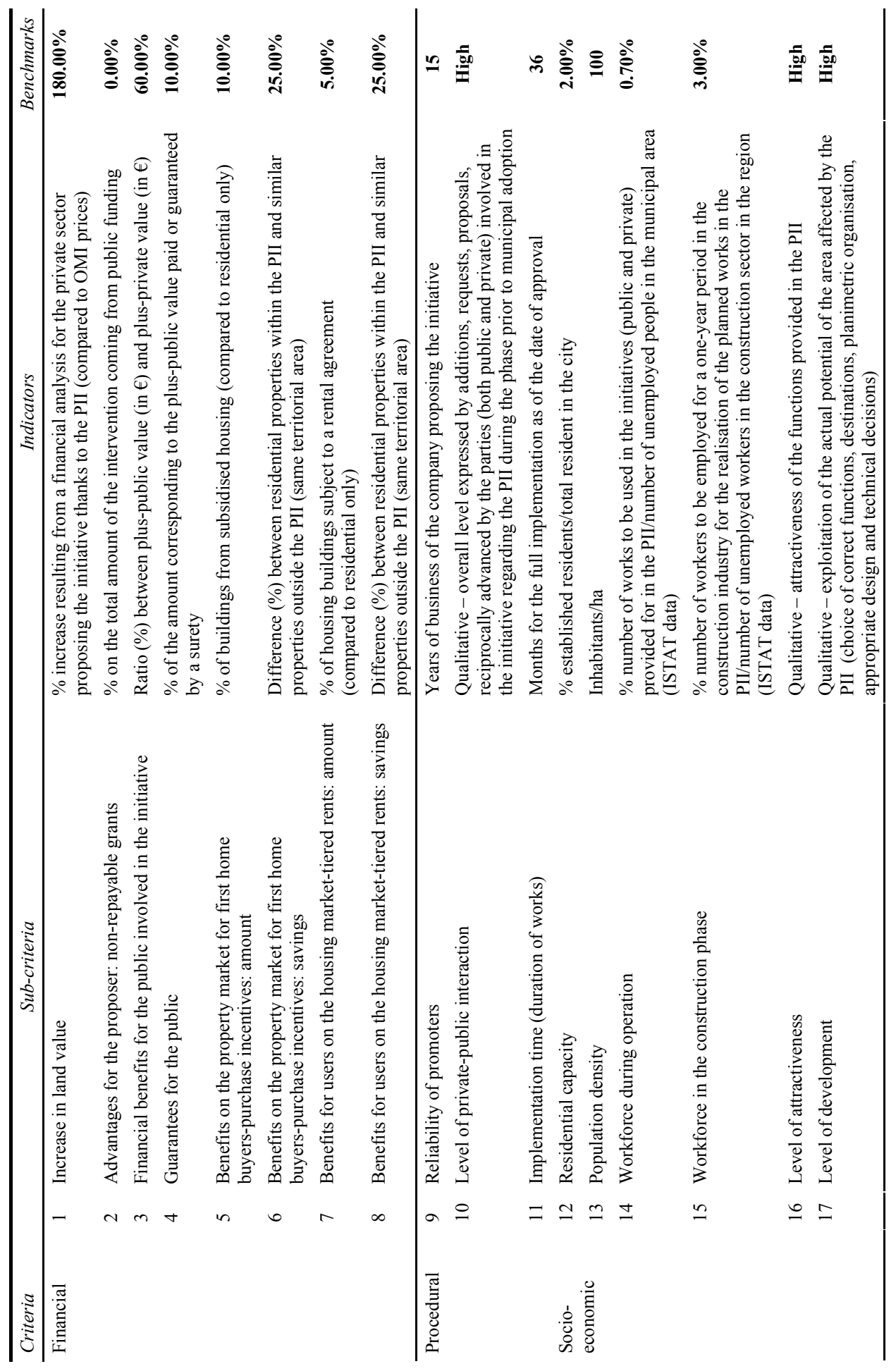


Table 17 Summary of benchmarks for each sub-criterion/indicator (continued)

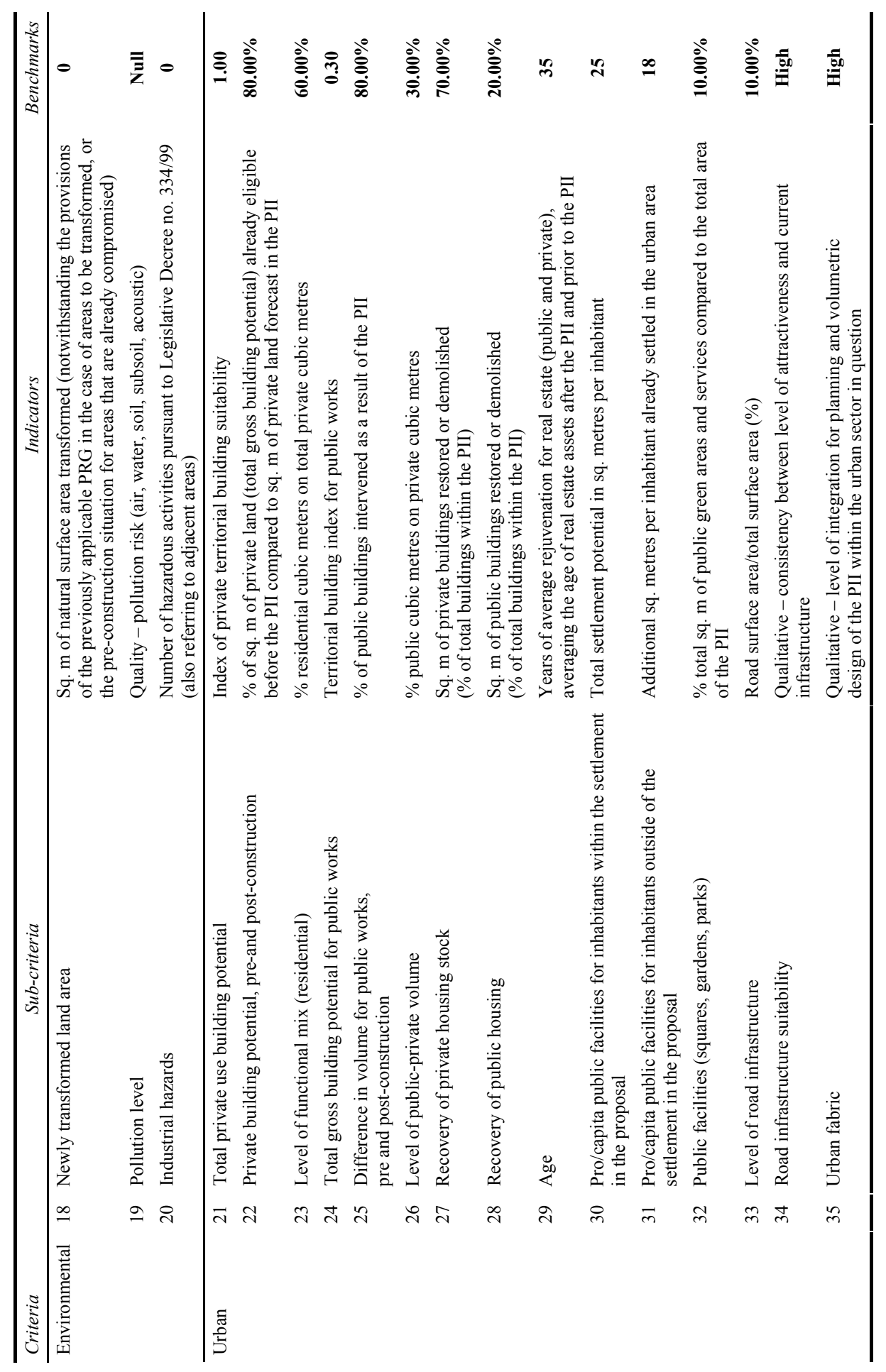




\subsection{Act}

\subsubsection{Pre-act: using the benchmarks}

In accordance with the procedure, the region must move forward to prepare guidelines, following the start of a full audit trail (technical and administrative) for the inputs and results of the methodology proposed for their final validation.

\subsubsection{In-act: institutionalisation of the BME}

The in act phase, as described in Section 3, will commence only when the 'guidelines' are outlined within a regulatory framework.

\section{Conclusions}

The proposed BME methodology, built up by implementing into a new and unique procedure two analysis and evaluation approaches - the MCA and BCM, applicable to any type of territorial redevelopment process based on the PPPN, was operationally tested on a specific type of PPPN process, the PII of the Lazio Region, verifying the possibility of defining benchmarks, as performance thresholds capable of generating satisfaction, shared among stakeholders.

Hence, the outlined methodological approach, that became operational in the testing of the proposed method has permitted translating these expectations into reference elements to build benchmarks that represent a balanced composition and that may allow the PA (local, provincial and regional) a more virtuous management of settlement redevelopment and recovery processes based on the PPPN (PII in the testing). Thus, as already mentioned, the BME enables the synthesis of different interests expressed through a 'rational' observation of reality and not referred to abstract expectations.

In a specific PPPN process, if certain framework conditions (of a defined spatial area at a specific point in time) have enabled some initiatives (best in class) to achieve certain performance levels for which the stakeholders have expressed satisfaction, and if those framework conditions persist, new initiatives with performance levels comparable (if not superior) to past initiatives, which were considered the best and most satisfactory, can and should be provided. Consequently, the new PPPN programming and the relative initiatives should provide for the attainment of the same satisfactory performance levels. Consequently, in the programming of the PII and related initiatives, the achievement of those very same satisfactory performance levels identified by the benchmarks can be entered as an objective. Generally speaking, and particularly in the application, the benchmarks, and in particular those identified with the application of the BME to the PII, are closely linked to the local context of the proposed initiatives, representing a synthesis between the practices, legislation, expectations and priorities of stakeholders.

Consequently, when forms of PPPN are used in settlement redevelopment processes, the proposed method may be an opportunity for PAs to have a greater guarantee of producing development, being competitive, boosting the economy and improving the quality of life of a community (Battisti, 2012). 


\section{Acknowledgements}

The contribution is the result of joint work of the two authors. Although the scientific responsibility attributable in equal parts to all two authors, the following sections: abstract, 1, 3.1, 3.3 Plan, 3.3 Check, 4.3, 4.5, have been drawn up by M.R. Guarini; the following sections: 2, 3.2, 3.3 Do, 3.3 Act, 4.1, 4.2, 4.4, 5 have been drawn up by F. Battisti. This article is a summary and reworking of $\mathrm{PhD}$ Thesis Valutazioni comparative per lo sviluppo dei processi di riqualificazione del territorio a partenariato pubblico-privato: una proposta di metodo. Sperimentazione sui Programmi Integrati di Intervento della Regione Lazio in Doctoral School of 'Redevelopment and Settlement Recovery' (XXIV cycle), Sapienza University of Rome, author F. Battisti, tutor M.R. Guarini.

\section{References}

Battisti, F. (2012) Valutazioni comparative per lo sviluppo dei processi di riqualificazione del territorio a partenariato pubblico-privato: una proposta di metodo. Sperimentazione sui Programmi Integrati di Intervento della Regione Lazio, PhD Thesis in Doctoral School of 'Riqualificazione e Recupero Insediativo' (XXIV ciclo), Tutor Prof.ssa M.R. Guarini, Fa-coltà di Architettura, Sapienza University of Rome [online] http://padis.uniroma1.it/handle/ $10805 / 2088$ (need to request access to the file).

Camp, R. (1996) Business Process Benchmarking: trovare e migliorare le prassi vincenti, Editoriale Itaca, Milan.

Curti, F. (2007) Lo scambio leale. Negoziazione urbanistica e offerta privata di spazi e servizi pubblici, Officina, Rome.

European Commission (1997) Benchmarking: Implementation of an Instrument Available to Economic Actors and Public Authorities, Communication from the Commission to the Council, the European Parliament, the Economic and Social Committee and the Committee of the Regions, COM (97) 153 final, 16 April 1997, Bruxelles.

European Commission, Europe Aid Cooperation Office (2005) Linee guida per l'analisi multicriteria (UE), Quando e perché l'analisi multicriteria dovrebbe essere utilizzata, Bruxelles.

Fusco Girard, L. and Nijkamp, P. (2012) Le valutazioni per lo sviluppo sostenibile della città e del territorio, Franco Angeli, Rome.

Guarini, M.R. and Battisti, F. (2014a) 'Evaluation and management of land-development processes based on the public-private partnership', Advanced Materials Research, Vols. 869-870, pp.154-161, Trans Tech Publications, Switzerland, ISSN: 10226680, ISBN 978-303785975-9, doi: $\quad 10.4028 /$ www.scientific.net/AMR.869-870.154, 13 December 2013 [online] http://www.scientific.net/AMR.869-870.154.

Guarini, M.R. and Battisti, F. (2014b) 'Benchmarking multi-criteria evaluation: a proposed method for the definition of benchmarks in negotiation public-private partnerships', in Murgante, B. et al. (Eds.): ICCSA 2014, Part III. Lecture Notes in Computer Science, Vol. 8581, pp.208-223, Springer International Publishing, Switzerland, doi: 10.1007/978-3-319-091501 13.

Karloff, B. and Ostblom, S. (1993) Benchmarking: a Signpost to Excellence in Quality and Productivity, Wiley, Chichester.

Keeney, R.L. and Raiffa, H. (1993) Decisions with Multiple Objectives: Preferences and Value Tradeoffs, John Wiley, New York, Republished by Cambridge University Press, New York.

Lichfield, N., Barbanente, A., Borri, D., Khakee, A. and Pratt, A. (1998) Evaluation in Spatial Planning: Facing the Challenge of Complexity, Kluwer Academic Publishers, Dordrecht. 
Mattia, S. (2007) Costruzione e valutazione della sostenibilità dei progetti, Vols. 1 e 2, Franco Angeli, Rome.

Morano, P., Locurcio, M., Tajani, F. and Guarini, M.R. (2014) 'Urban redevelopment: a multi-criteria valuation model optimized through the fuzzy logic', in Murgante, B. et al. (Eds.): ICCSA 2014, Part III. Lecture Notes in Computer Science, Vol. 8581, pp.161-175, Springer International Publishing, Switzerland, doi: 10.1007/978-3-319-09150-1_13.

Morano, P. and Tajani, F. (2013) 'Bare ownership evaluation. Hedonic price model vs. artificial neural network', International Journal of Business Intelligence and Data Mining, Vol. 8, No. 4, pp.340-362, doi: 10.1504/IJBIDM.2013.059263.

Morano, P. and Tajani, F. (2014a) 'Urban renewal and real option analysis, a case study', 14th International Conference on Computational Science and Its Applications, ICCSA 2014, Lecture Notes in Computer Science, Vol. 8581, pp.148-160, Springer International Publishing, Switzerland, doi: 10.1007/978-3-319-09150-1_12.

Morano, P. and Tajani, F. (2014b) 'Least median of squares regression and minimum volume ellipsoid estimator for outliers detection in housing appraisal', International Journal of Business Intelligence and Data Mining, Vol. 9, No. 2, pp.91-111, ISSN: 1743-8187, doi: 10.1504/IJBIDM.2014.065074.

Nijikamp, P., Rietveld, P. and Voogd, H. (1990) Multicriteria Evaluation in Physical Planning, North Holland Publ., Amsterdam/New York.

Roscelli, R. (2005) Misurare nell'incertezza. Valutazioni e trasformazioni territoriali, Celid, Turin, ISBN: 88-7661-664-0.

Urbani, P. (2007) Territorio e poteri emergenti. La politica di sviluppo tra urbanistica e mercato, Giappichelli, Turin.

\section{Notes}

1 Urban Pilot Projects Urban I (1994-1999) and Urban II (2000-2006) are among the PPPN experiences carried out at European level.

2 The use of the following instruments is indicated for implementation of PPPT at European level: design build finance transfer, service contracts, management contracts, build lease transfer, design build finance operate, concession, build operate own, etc.; in the specific Italian situation, the following have been implemented: project financing, leasing in building, building and management concessions.

3 The complex programmes were established by Law No. 179/1992, and were subsequently implemented by the regions with specific standards.

4 The objective of PAs is to increase collective benefits, while private parties are oriented towards maximising revenues, profits and extra-profits through the opportunity to implement initiatives through the same variant of the planning instrument.

5 At the regional level, there is only one significant experience conducted by the Marche Region (2009), which issued the Implementing Regulation of Regional Law No. 16 of 2005 concerning 'regulation of urban redevelopment projects and strategies for ecologically equipped productive areas'. The regulation provides both criteria for determining the level of public interest in urban redevelopment projects and criteria and parameters to comprehensively assess initiatives related to redevelopment programmes. The regulation also provides benchmarks, or performance thresholds, that the initiatives must follow.

6 A particular case is that of the City Council of Rome which, in 2011, entrusted the task of preparing a study to define a 'Protocol for the Urban Quality of Rome Capital' to the Urban Brownfield Areas Association (AUDIS) (City Council Memorandum 6830, 5 May 2011). The work of defining the 'Protocol for the Urban Quality of Rome Capital', conducted through the comparison of public parties, private operators, scholars and social stakeholders involved in the urban redevelopment plans and projects was based on the 'Charter of the Quality of Urban Renewal' published by AUDIS in 2008. The 'Protocol for the Urban Quality of Rome Capital' 
defines and evaluates the quality of complex urban projects was presented in Rome on 22 May 2012 in the Pietro da Cortona room of the Campidoglio.

7 The main assessment techniques and instruments indicated in European directives are: multi-criteria analysis, cost-benefit analysis, SWOT analysis, benchmarking, techniques for participation, interaction and conflict resolution, and fuzzy analysis.

8 It is possible to consult some guidelines for the use of benchmarking, promoted by the European Commission, based on the Benchmarking methodology at http://ec.europa.eu/ internal_market/securities/benchmarks/index_en.htm.

9 It is possible to consult some cases for use of the MCA, promoted by the European Commission, at $\mathrm{http} / /$ ec.europa.eu/europeaid/evaluation/methodology/tools/too_cri_som en.htm.

10 The European Commission specifies the cases in which the different MCA techniques can be used in assessments (ex ante, in itinere and ex post) and the methods and conditions for the best expression of their potential and for their correct use.

11 In the Italian legislation system, the use of some MCA techniques is only contemplated in Legislative Decree No. 163 of 2006 in order to select the most economically advantageous offer in the tenders of public works.

12 Inclusive, because they contemplate the active participation of various stakeholders.

13 Complex, because they take into account different and heterogeneous aspects.

14 Without prejudice to the reform of local authorities currently (2014) before the Italian Parliament, in the framework of the activities for which the PAs are responsible:

a Presidential Decree No. 8 of 15 January 1972 and Presidential Decree No. 616 of 14 July 1977 gave Regions legislative powers in relation to urban planning

b with reform of Chapter V of the Constitution (from 2001), provinces were given territorial and provincial planning responsibilities

c pursuant to Chapter V of the Constitution (from 1948), municipalities were given local territorial government powers.

15 It is considered appropriate to briefly summarise the difference between best in class and best practices, terms that are sometimes used interchangeably. As part of a limited sample of initiatives, best in class means those initiatives that are positively the most significant; generally, best practices includes the most significant positive experiences with reference to a non-limited and broader set of initiatives. The difference lies in the size of the framework in which the significance of a certain experience/initiative is recognised.

16 The term 'protocol' refers to a pre-defined behaviour pattern within an activity that describes a rigid sequence of behaviours. It is a document that provides a sequence of actions that must be carried out to achieve the given objective. In this case, 'standard' refers to values expressed by an indicator with which the frequency of activities or services rendered or the performances of the intervention identified are defined by using a scale as a reference measure. This term has a normative meaning associated with an explicit quality opinion. Procedure means a set of professional actions aimed at the set objective, or a sequence of actions that are more or less rigid that describe individual process phases to harmonise activities and behaviours by reducing individual discretion.

17 The possibility of consulting the PPPN documentation in the archives of the Directorate for Territorial and Urban Development of the Lazio Region is provided by the Research Collaboration Agreement initiated between the Department of Architecture and Design (DIAP) of the University of Rome 'Sapienza' and Directorate for Territorial and Urban Development.

18 Note that it was not possible to verify the situation concerning the PRIU initiated in the City of Rome. 
19 The data which are absent in Table 8 were not found in the material provided by the Directorate for Territorial and Urban Development of the Lazio Region; in particular, for some PII it was not possible to find any information related to a chronological number and year of presentation. A clarification in terminology should be provided to allow for the comprehension of various 'inconsistencies' detected in the data: for the column defining the 'procedural status' (data provided by querying the list of PII procedures in the database of the Directorate for Territorial and Urban Development of the Lazio Region), the term 'approved' signifies a PII approved by the regional council; the term 'favourable' refers to a PII which received a favourable preliminary inquiry. However, in some cases, PII initiatives which were listed as 'favourable' have also been approved. This 'inconsistency' is derived from the necessary delay in updating the technical department's database with the 'political' activities of the regional council.

20 Environmental aspects were not taken into consideration, since the environmental impact assessment procedure (strategic environmental assessment and environmental impact assessment, where applicable) for this type of initiative follows an independent process and, as such, does not fall within the domain of the Directorate for Territorial and Urban Development, but rather of the Directorate for Environmental Protection. It was therefore not possible to access the documentation related to the environmental aspects of the PII initiatives.

21 This estimate was carried out by surveying the residential units inhabited, relative to the intervention.

22 For the case studies see Battisti (2012), note no. 131.

23 The decision to indicate only three sub-criteria is due to the fact that the PII must be subjected to a mandatory VAS verification, pursuant to art. Twelve of Legislative Decree No. 152/2006 (Consolidated Text on the Environment) and where applicable, in the case of non-exclusion, a VAS. In the VAS procedure are deeply evaluated the effects of the programme on the environment.

24 The stakeholder analysis was implemented within the Directorate for Territorial and Urban Development of the Lazio Region, interviewing subjects (belonging to different categories of stakeholders) who attended services conferences held at the regional headquarters.

25 Where the optimal objective function falls within a range of reference values, the summary reference values for the objective function must be defined through the arithmetic mean of all values indicated in the interviews.

26 This software allows for the automatic checking of the internal consistency of the matrix, i.e., its reliability: indeed, human capacity presents a certain limitation in establishing relationships between elements, and may find it difficult to maintain a consistent judgement in all pairwise comparisons. In fact, to be consistent, the preferred judgements should respect properties of reciprocity and transitivity.

27 Since the objective functions can, for the same sub-criterion, differ from the stakeholders, it follows that for each of them the values associated with the best performances are different and related to their objective functions. To arrive at a value for the best shared performance, the prevalent objective functions were identified (corresponding to the majority of stakeholders): the maximum value proposed is therefore relative to the prevalent objective function.

28 Until the contextual conditions (permanence of conditions) that have allowed the achievement of a performance remain, it can be expected that the same performance will be attained once again, and even exceeded. Hence the importance of applying the BME cyclically in order to define the benchmarks which have appeared in time frames as close as possible to the programming of the new redevelopment programme, with a greater chance of 'permanence of conditions', and therefore validity. 